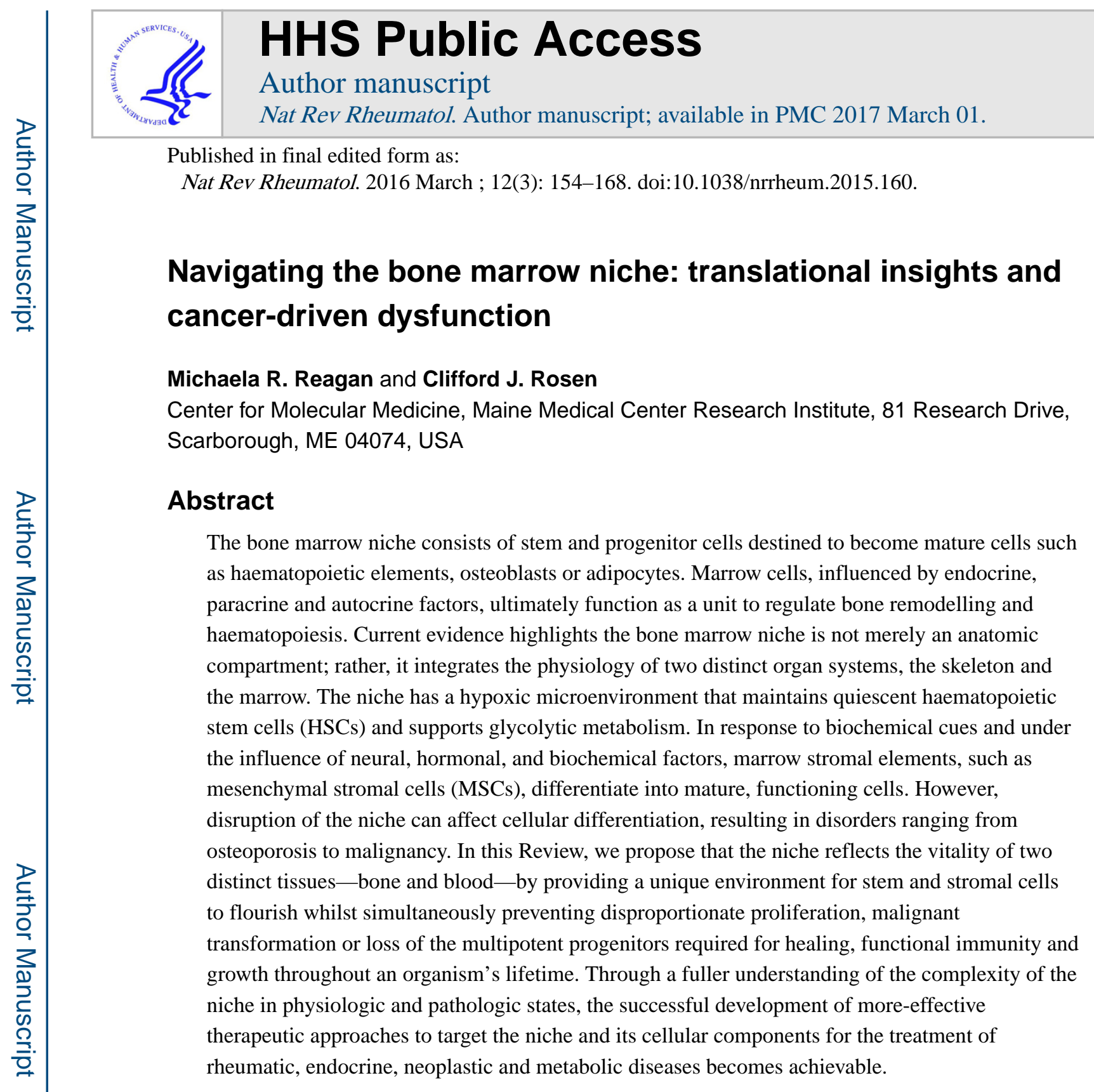

\title{
Introduction
}

Bone marrow is a remarkable multifunctional tissue that contains stem, progenitor and mature cells of several lineages. Stem cells have, by definition, the capacity to self-renew and differentiate into many different types of cells. ${ }^{1}$ Haematopoietic stem cells (HSCs) are multipotent cells that differentiate into myeloid, lymphoid and erythroid lineages and have short-term or long-term regenerative capacity. By contrast, bone marrow cells of purely mesenchymal origin—that is, mesenchymal stromal cells (MSCs)—considered within a

Correspondence to: M.R.R., MReagan@mmc.org.

COMPETING INTERESTS

The authors declare no competing interests.

AUTHOR CONTRIBUTIONS

Both authors contributed equally to researching data for the article, discussion of content, writing and review/editing of manuscript before submission. 
strict definition based on cell-surface markers and function (Table 1), includes cells capable of tissue culture plastic adherence and expansion but excludes the non-stromal elements of the marrow such as osteoclasts, macrophages, and endothelial cells. ${ }^{2}$ The bone marrow 'stem cell niche' refers to the unique microenvironment of these regenerative cells in the bone marrow. This niche forms an anatomical and functional unit of physiology that integrates endocrine, autocrine, and paracrine signalling to serve the needs of the whole organism by sustaining the stem cell pool. ${ }^{3}$

Mobilization and export of HSCs from the bone marrow can occur with injury, acute inflammation or biochemical stress, or during tissue repair. The stem cell pool that remains in the bone marrow after stress-induced haematopoiesis is essential for its repopulation and revitalization. In this Review, we summarize the unique physiological aspects of the bone marrow niche and the consequences of its alteration. In addition, we examine this microenvironment as it relates to cancer cells that invade and hijack the function of the niche. ${ }^{4-6}$

\section{Function and anatomy of the niche}

\section{Functional aspects}

The bone marrow niche has several functions including the production of blood-forming elements, the modulation of skeletal remodelling, and the maintenance of HSCs. HSCs have the unique capacity to give rise to all mature blood cell types and are self-renewing; that is, during asymmetric division a proportion of the daughter cells remain HSCs, such that the pool of these cells is not depleted. Within the HSC pool are transient self-renewing HSCs and long-term quiescent HSCs. By contrast, bone marrow MSCs that regulate bone remodelling are multipotent, self-renewing progenitor cells that can differentiate into other cell types (e.g. osteoblasts, adipocytes or chondrocytes). ${ }^{7} \mathrm{HSC}$ quiescence is strongly dependent on MSCs and MSC-descendants, illustrating an important role for MSCs in the bone marrow niche. ${ }^{8}$

The delicate balance between HSCs and MSCs provides a critical integration point between the marrow and the skeleton. In physiologic states, as well as in injury and chronic diseases, several types of progenitor cells are required to perform very specific functions beyond bone remodelling and maintenance of haematopoiesis. Importantly, roles for the niche in modulating tumour biology and immunity have also emerged, further enhancing its importance but also emphasizing its complexity.

\section{Location and organization}

Defining the physical location of the bone marrow niche can be challenging because of considerable inter-individual and inter-species differences in the bone marrow. Classically, the principal bone marrow niche component is that which supports the cells that ultimately define haematopoiesis; that is, HSCs, which are destined for differentiation and subsequent export into the circulation. ${ }^{9}$ Today the bone marrow niche is reconsidered within the functional context of MSCs, which are essential for maintaining a stable pool of osteoblast progenitors for bone remodelling. ${ }^{10,11}$ Human and rodent MSCs have been used 
experimentally as therapeutic tools to hasten fracture repair or injury recovery in many tissues. ${ }^{11,12}$ Enhanced MSC differentiation into the osteogenic lineage has been directly linked to the maintenance of HSCs in their quiescent state. ${ }^{13}$ Still, the balance between quiescence, self-renewal, and differentiation of HSCs in the bone marrow niche is dynamic, and modulated in part by MSCs. Hence, what has emerged is a new concept of dual stem cell populations that share a common location, with an interdependent relationship of both mutual support and competition for the marrow space. ${ }^{14}$

Anatomically, the niche is more than a series of HSCs clinging to MSCs and osteoprogenitors within a flat marrow space. Rather, it is a 3D structure adjacent to the perivascular (or sinusoidal) space created by endothelial cells, in close proximity to trabecular bone and other cells. ${ }^{15,16}$ In addition to those components, the niche also has matrix elements and microvessels that probably have regulatory capacities, particularly with respect to the unique biochemical composition of the milieu (see later). In that vein, the niche can be considered as two mini organ systems interacting at a single site that has very specific environmental characteristics (Figure 1). ${ }^{17}$ Notwithstanding this concept reconciling the role of trabecular bone with haematopoiesis remains a challenge. However, the identification by Bianco, Robey and others of the cellular phenotype of multipotent MSCs (CD146 ${ }^{+}$expressing adventitial cells adjacent to sinusoids) and emerging evidence of the role of bone lining cells has allowed for a more-complete understanding of the organization of the haematopoietic niche, and the importance of MSCs and the endosteal surface of trabecular bone, to the production of differentiated marrow elements. ${ }^{7,18,19}$

\section{Cellular components}

As well as HSCs and MSCs, several other cellular components of the bone marrow have been recognized as critical for the maintenance of a healthy niche. The aforementioned cells include bone lining cells, osteoblasts, marrow adipocytes, resident tissue macrophages ('osteomacs'), immune cells, canopy cells, and neurons, which are discussed respectively in this section. These cells are simultaneously reliant on the niche and essential for its function.

Bone lining cells on the endosteal surface that express transcription factor $\mathrm{Sp} 7$ (also known as osterix) are precursors to osteoblasts and osteocytes. ${ }^{20}$ These cells have been difficult to characterize but generally are flat and fibroblastic in appearance. They could have an important role in replacing bone-forming cells during physiologic remodelling and in response to anabolic therapies such as parathyroid hormone (PTH) ${ }^{21}$. Whether these cells can also differentiate into adipocytes remains to be proven but raises the interesting concept of a secondary pool of multipotent MSCs within the niche proper.

Osteoblasts are critical regulators of HSC fate within the bone marrow niche. ${ }^{22}$ These cells are in close proximity to HSCs; moreover, regulatory factors that enhance MSC differentiation into the osteoblastic lineage can also promote the development of the bone marrow niche as well as the expansion and egress of HSCs. ${ }^{23}$ The Kronenberg group was one of the first to establish the importance of osteoblasts in maintaining HSCs within the niche. ${ }^{13}$ The same group also showed that recombinant PTH stimulated expansion and egress of HSCs, and that constitutive upregulation of the PTH-PTH-related peptide (PTHrP) receptor in osteoblasts disrupted normal haematopoiesis. ${ }^{24}$ Ten years later, Coskun and 
colleagues showed that lack of Sp7 in osteoblast-lineage cells allowed for vascularization of developing bone marrow, but HSC proliferation and differentiation potential were significantly impaired. ${ }^{25}$ In addition, Omatsu et al. ${ }^{26}$ reported that FoxC1 expressed in osteoprogenitor and CXCL12-abundant reticular (CAR) cells was essential for maintenance of haematopoietic stem and progenitor cells in vivo. Thus, MSCs, osteoblasts and their progenitors are essential components for niche homeostasis.

Marrow adipocytes, which reside close to the endosteal surface, were long considered 'filler' for the marrow compartment. This notion was based on anatomical studies of marrow from patients with age-related osteoporosis, aplastic anaemia, myelodysplasia, and after radiation or chemotherapy, ${ }^{27}$ in which adipocytes were abundant within fibrotic or empty marrow spaces. ${ }^{28,29}$ However, work in the past 3 years has demonstrated a much more complicated role for the adipocyte within the bone marrow niche. ${ }^{30}$ For example, there are probably two major types of marrow adipose tissue (MAT): one that is found in the distal tibia and tail of rodents and which is formed shortly after birth (constitutive MAT), and one that is noted later in life in the proximal femur and vertebrae in close proximity to haematopoietic elements and trabecular bone (regulated MAT). ${ }^{31}$ Constitutive MAT negatively regulates haematopoiesis, possibly by maintaining HSCs in a quiescent state, as shown in elegant experiments by the Daley group. ${ }^{32}$ In regard to the skeleton, constitutive MAT volume, as measured by use of osmium staining and microCT in rodents and MRI in humans, is inversely related to bone mass. ${ }^{33,34}$ By contrast, regulated MAT seems to be a more dynamic adipose tissue that has endocrine and paracrine effects on both the haematopoietic and skeletal remodelling systems. ${ }^{35} \mathrm{~A}$ high volume of regulated MAT is often, although not always, associated with low bone mass. ${ }^{36,37}$

Osteomacs (bone-marrow-resident macrophages; $\mathrm{F} 4 / 80^{+}$in mice, $\mathrm{CD} 68^{+}$in humans) are also pivotal to the maintenance of the endosteal bone marrow niche. ${ }^{38}$ Osteomacs facilitate the homing to bone, colonization, and dormancy of HSCs, ${ }^{39}$ and loss of osteomacs leads to the egress of HSCs into the blood. ${ }^{39}$ Osteomacs are distributed throughout the endosteum and periosteum and are vital to MSC osteogenic differentiation in vivo and in vitro, ${ }^{38,40}$ potentially contributing to the canopy covering the bone remodelling canopy (discussed later) in bone modelling sites. ${ }^{41}$ Winkler et al. ${ }^{39}$ suggest that osteomacs might also maintain haematopoietic progenitors in their stem-cell state whilst supporting endosteal bone formation. In support of that tenet, treatment with granulocyte colony-stimulating factor motivates HSCs to differentiate while at the same time depleting endosteal osteoblast and osteomac populations. ${ }^{39}$

Immune cells are an additional component of the bone marrow niche. Macrophages, neutrophils and myeloid-derived suppressor cells synergize to preserve the unique environment of the niche and protect it from cytotoxic lymphocytes. ${ }^{42}$ These innate immune cells are stress-responsive and thus can communicate with other cells within the niche to regulate HSC egress. In essence, the presence of this immunomodulatory network establishes a permissive environment that could enable colonization by foreign cells. This is sometimes referred to as 'bone-specific immunity' as the niche is an immune-privileged environment. ${ }^{43}$ The consequences of this specialized milieu are evident clinically in the 
frequent occurrence of tumour metastases in bone (see later), as well as serious infections such as tuberculosis involving this tissue prior to widespread dissemination. ${ }^{44}$

A 'canopy' or cellular membrane has been described that covers not only cuboidal osteoblasts in the periosteum but also the bone remodelling unit. ${ }^{45,46}$ This canopy might serve several functions beyond the insulation of bone cells from external stimuli or invasion. It might also be an important part of the niche, as it is composed of flattened cells and microvessels that provide nutrients and substrates for cells contained within that space, including MSCs, bone lining cells, osteoblasts, osteoclasts, and osteocytes. ${ }^{45,46}$ The precise relationship between the canopy and the niche has not been determined, in part because of the difficulty in defining both their anatomic locations and the lack of functional tools to trace canopy cell activity.

Finally, neural regulation of the niche and control of HSC export is mediated primarily through the sympathetic nervous system (SNS). The cyclic release of HSCs and expression of stromal cell-derived factor (SDF1, also known as CXCL12) and its receptor, CXCR4, are regulated by molecular clock genes, mediated by circadian secretion of noradrenaline from sympathetic nerves. ${ }^{47}$ These adrenergic signals are delivered locally by nerves in the bone marrow and transmitted to MSCs through $\beta 3$-adrenoceptors. Moreover, MSCs express a1B, $\alpha 2 \mathrm{~A}$, and $\beta 2$-adrenoceptors that make them responsive to norepinephrine and other signals that promote changes in their metabolic requirements. ${ }^{48}$ Activation of the SNS leads to the rapid downregulation of $C X C L 12$ expression and the export of HSCs and other types of immune cells into the circulation. $\beta 2$-adrenoceptors on MSCs can mediate changes in osteoblast differentiation and, ultimately, bone remodelling. ${ }^{48}$

\section{Biochemistry of the niche}

The bone marrow niche has its own unique biochemistry, supported by a rich vasculature that makes it particularly suitable for stem cells. The endosteal surface of each trabecula is surrounded by bone marrow with constituent progenitor and stem cell populations. The endosteum also contains pre-osteoblastic cadherin-2-expressing cells, and has nerve and blood supplies, ${ }^{49}$ although tese features are difficult to detect with plain-light microscopy. The heterogeneous environment of the endosteum contains scattered sites of microvascular infiltration associated with other regions of significant hypoxia, ${ }^{50}$ which are highly attractive regions for HSC-homing. ${ }^{51-53}$ Interestingly, quiescent HSCs tend to reside in areas of very low blood perfusion, whereas more proliferative HSCs with a lower reconstitution potential tend to prefer areas with greater blood flow. ${ }^{53}$ The hypoxic microenvironment in the endosteum is a major factor in the integration of skeletal and haematopoietic functions, owing in part to the central role of hypoxia-inducible factor (HIF)-1a in HSC differentiation. ${ }^{54,55}$

\section{Metabolic reprogramming in hypoxia}

Hypoxia induces a cellular response via a family of HIFs expressed in HSCs and MSCs that regulate a number of downstream signals. HIF transcription factors are composed of one of three oxygen-sensitive $a$-subunits-HIF-1a, HIF-2a or HIF-3a - and a constitutively expressed $\beta$-subunit, HIF-1 $\beta$, also called aryl hydrocarbon receptor nuclear translocator 
(ARNT) ${ }^{51}$ Once the HIF-a subunit binds ARNT, the binary complex translocates to the nucleus and activates the transcription of genes containing hypoxia-responsive elements (HREs). ${ }^{53}$ In normal oxygen conditions, or when $\mathrm{O}_{2}$ concentration exceeds 5\%, HIF-1a protein is degraded by the proteasome within 5 min. ${ }^{56,57}$ Three prolyl hydroxylase domain (PHD) enzymes hydroxylate two residues within the oxygen-degradation domain of HIF-1a, leading to ubiquitination and subsequent degradation of the HIF complex ${ }^{56}$ Pharmacologic approaches to inhibit PHD proteins and stabilize HIF-1a are currently in clinical trials for the treatment of anaemia caused by chronic kidney disease and to enhance stem-cell pools after chemotherapy and radiation therapy. ${ }^{52}$

Survival and maintenance of HSC stemness in hypoxia requires substantial metabolic adaptations. As noted above, relative hypoxia (in which $\mathrm{O}_{2}$ concentration may be as high as $5 \%$ ) induces the stabilization of HIF-1a in HSCs as well as the transcription of multiple downstream target genes including VEGFA. ${ }^{58}$ Metabolic reprogramming of quiescent cells is necessary to prevent differentiation and this reprogramming occurs through a shift from oxidative phosphorylation to glycolysis. ${ }^{59,60}$ Importantly, glycolysis, although less-efficient than mitochondrial oxidation in generating ATP, reduces oxidative stress and generation reactive oxygen species (ROS), both of which drive stem cell differentiation. Indeed, HSCs are particularly well-suited to tolerate oxidative stress through a well-organized antioxidant defense system.

MSCs also express HIF proteins and respond to hypoxia similarly to HSCs, with the upregulation of multiple HIF-inducible genes following translocation of the transcription factor complex to the nucleus. ${ }^{57}$ Enhanced HIF-1a protein expression promotes osteogenic differentiation over adipogenesis in the marrow, ${ }^{61}$ potentially via increased production of vascular endothelial growth factor (VEGF)-A, which is a potent angiogenic factor, and its subsequent suppression of peroxisome proliferator-activated receptor $\gamma$ (PPAR- $\gamma)$. VEGF-A has been shown to be essential for endochondral bone formation in vivo, and for MSC differentiation into osteoblasts through binding to VEGF receptor $2 .{ }^{62}$ Other HIF-inducible proteins in MSCs include lactate dehydrogenase A (LDH-A), phosphoglycerate kinase and glucose transporter 1 (GLUT1), all of which are essential for the promotion of glycolysis over oxidative phosphorylation and, ultimately, for osteogenic differentiation. ${ }^{61,63}$

Two key proteins, GLUT1 and LDH-A, are both upregulated during hypoxia conditions in HSCs and MSCs via activation of the transcription factor HIF-1a. As noted, mitochondrial respiration must be suppressed to enable glycolysis to predominate; this suppression occurs through the hyperactivation of AMP kinase (AMPK) and downregulation of several relevant mitochondrial genes, as well as the suppression of ROS production. Activation of AMPK by metformin, an anti-diabetes drug, enhances glycolysis, but also suppresses HSC differentiation and maintains the stemness of these cells. ${ }^{59,64}$ By contrast, metformin has been shown to enhance MSC differentiation, also through AMPK, by upregulating the master osteogenic transcription factor RUNX2. ${ }^{65}$ Studies from independent laboratories have confirmed that osteogenic differentiation is driven almost exclusively by glycolysis and that GLUT1 is essential to that process. ${ }^{66,67}$ Moreover, PTH, which can enhance HSC egress and MSC differentiation, works by inducing glycolysis in differentiated osteoblasts, probably through upregulation of GLUT1 and GLUT3 expression. ${ }^{68}$ Overall, it is clear that 
the bioenergetics of cells in the niche, driven by ATP demand, help determine how specific transcriptional factors induce the differentiation of stem and progenitor cells.

\section{Effects of growth factors}

Biochemical changes in both HSCs and MSCs also occur as a result of vascular and paracrine delivery of cytokines and chemokines. For example, HSC mobilization occurs because of key receptor-ligand interactions, particularly SDF1-CXCR4 ${ }^{69}$ Other ligands and their receptors are also integrated within the bone marrow niche, including integrin a-4VCAM1 (vascular cell adhesion protein 1), L-selectin (CD62L)-PSGL-1 (P-selectin glycoprotein ligand 1, or CD162) hyaluronic acid (HA)-CD44, and mast/stem cell growth factor receptor Kit (c-Kit, or CD117)-Kit ligand. ${ }^{70}$ Ephrin type-B receptor 4 (EPHB4) is a tyrosine kinase receptor that has been shown to modulate HSC fate through its ligand ephrin-B2. ${ }^{71}$ In sum, it is apparent that growth factors signal the egress of HSCs from the marrow and also probably encourage the use of alternative metabolic pathways to support differentiative function or, in some cases, to inexorably alter stem-cell fate.

\section{Consequences of niche disruption}

The intricate balance between HSCs and MSCs is subject to disruption by many factors, including tumour-cell invasion, excessive ROS production, substrate insufficiency and a host of drugs used to treat autoimmune diseases that might unintentionally harm the niche. Pathologic changes in MSC differentiation can also alter the niche and lead to activation of tumorigenesis via the Notch signalling pathway. For example, in a 2014 study, Krevvata et al. ${ }^{72}$ demonstrated that constitutive activation of $\beta$-catenin interacts with Foxo1 in osteoblasts and MSCs, which in turn enhances the expression of the Notch ligand protein jagged-1. In long-term repopulating HSCs, chronic exposure to jagged-1 results in leukaemic transformation. ${ }^{73}$

\section{Cancer-related disruption of the niche}

\section{Niche colonization by tumour cells}

The unique properties of the bone marrow niche make it exceptionally conducive to colonization by tumour cells (Figure 2a): the niche can be considered as 'fertile soil' for malignant cell 'seeds'. Breast cancer, prostate cancer and multiple myeloma cells strongly prefer to metastasize and grow within the bone marrow rather than other anatomical locations, not only because of its characteristic properties described above, but also due to positive-feedback loops initiated by tumour cells within the niche. By causing osteolytic (bone-destructive, common in breast cancer and multiple myeloma) or osteoblastic (boneforming, common in prostate cancer) lesions, cellular crosstalk is initiated that supports tumour growth and uncoupling of bone remodelling. As reviewed elsewhere, osteolytic cancers induce a forward-feedback loop termed the 'vicious cycle', in which boneembedded growth factors, extracellular matrix proteins, and calcium are released as bone is resorbed, which then signal to tumour cells, accelerating their proliferation. ${ }^{74,75}$ When receptor activator of $\mathrm{NF} \kappa \mathrm{B}$ (RANK) on pre-osteoclasts is stimulated by RANK ligand (RANKL), produced by osteoblasts and tumour cells, osteoclast number and activity are increased, which directly supports multiple myeloma cells. ${ }^{76}$ Osteoclastogenesis then leads 
to bone degradation via resorption pits and proteinases, such as cathepsin $\mathrm{K}$, which can also be produced by tumour cells. ${ }^{77}$ RANKL itself has also been identified as a tumour chemokine, ${ }^{78}$ creating an intricate web of signalling interactions between osteoblasts, osteoclasts, and tumour cells.

As tumour cells take hold and begin to grow in the favourable conditions of the bone marrow, they modulate and usurp the marrow to support their own growth at the expense of normal bone homeostasis, leading to increased fractures, hypercalcaemia, spinal cord compression, immune cell dysfunction, pain, and, eventually, death. ${ }^{79}$ The microenvironment not only is required for this process, but also changes in response to tumour growth. For example, MSCs from patients with multiple myeloma and myelodysplastic syndrome are abnormal due to the effects of local tumour cells, and have inhibited osteogenesis and increased tumour-supportive functions, which are driven through numerous mechanisms. ${ }^{80-82}$ Similarly, leukaemic myeloid cells also 'hijack' the normal osteogenic process by stimulating MSCs to overproduce functionally altered osteoblastlineage cells, which accumulate in the bone marrow cavity as inflammatory myelofibrotic cells. ${ }^{83}$ These myeloproliferative neoplasia-associated osteoblasts, in turn, exhibit decreased expression of many HSC-retention factors and have a severely compromised ability to maintain normal HSCs, but are more efficient at harbouring laeukemia stem cells. ${ }^{83}$ Targeting this pathological interplay between osteoprogenitor-lineage cells and tumour cells represents a key avenue to treat myeloproliferative disease or bone metastasis. Hence, the 'fertile soil' of the bone marrow is not only responsible for the successful growth of tumour cell 'seeds', but is also, by the same metaphor, fertilized further by the tumour cells themselves, as they create a more hospitable environment for further tumour colonization and expansion.

\section{Facilitating tumour survival}

The bone marrow also provides protection from anti-cancer therapies through cell adhesionmediated drug resistance (CAM-DR). This resistance is, in part, due to the quiescent state induced in cells within the bone marrow niche, which allows for long-term survival of malignant cells. The ability of the bone marrow niche to revert cells to a stem-cell state can cause tumour cells that are no longer clonogenic to revert to a stem-like state after signalling from the bone marrow via myofibroblast-derived factors such as hepatocyte growth factor. ${ }^{84}$ Thus, cancer cell stemness is not a fixed state, but can be instilled and nurtured by the niche. The niche also provides numerous growth factors that facilitate tumour quiescence or growth; precisely what dictates tumour cell fate (that is, apoptosis, dormancy, self-renewal, or proliferation) is still unclear. ${ }^{85}$ Importantly, the plasticity of differentiation that is characteristic of putative cancer stem cells (CSCs), which can be driven by bone marrow interactions, suggests that eradicating CSCs would not stop tumour growth as more CSCs could be reinitiated from dedifferentiation of non-stem cells upon association with the niche. ${ }^{86}$ Although evidence for this mechanism is clear with leukaemia-initiating stem cells, ${ }^{84}$ the presence of stem cells or tumour-initiating cells remains controversial in other cancers, such as multiple myeloma, and hence the role of the bone marrow is likely to be dependent on tumour type and clonal properties.

Nat Rev Rheumatol. Author manuscript; available in PMC 2017 March 01. 
Many molecules, including matrix metalloproteinases, VEGFs, activin-A, and connective tissue growth factor facilitate tumour survival in the bone marrow and can act as cellnonautonomous factors. ${ }^{87,88}$ Bone-derived factors such as the transforming growth factor (TGF)- $\beta$ family cytokines and insulin-like growth factors stimulate tumours to activate osteoblasts via molecules such as VEGF, platelet derived growth factor (PDGF), and endothelin-1. ${ }^{88,89}$ TGF- $\beta$ (through Smad pathway signalling), hypoxia (through HIF-1a), and extracellular calcium (through Akt and MAPK pathways) alter gene expression within tumour cells in the bone microenvironment, enabling the survival and growth of these cells in the marrow cavity. ${ }^{88,90,91}$ Many osteolytic tumour cells produce PTHrP, TGF- $\beta$, dickkopf-1, sclerostin, and RANKL; moreover, osteoblastic tumours often secrete bone morphogenic proteins and other growth factors (such as fibroblast growth factors and Wnt family members), but many of the mechanisms of osteoblastic lesion development remain undetermined. ${ }^{92}$ Metabolic changes in tumour cells induced by their local microenvironment are also now recognized as important contributors to tumour growth and potential therapeutic targets. 93

\section{Effects of bone marrow cells on tumours}

The many cells that contribute to the 'fertile soil' of the niche have been reviewed previously and described above. ${ }^{75,94,95}$ Just as these cellular elements of the bone marrow are important in supporting and regulating the haematopoietic niche, they also have roles in the promotion, and perhaps the inhibition, of tumours within the bone marrow. For example, myeloidlineage progenitor cells $\left(\mathrm{CD}_{1} 1 \mathrm{~b}^{+}\right)$, have been shown to support tumour growth, migration, and invasion in vitro and, when co-implanted with tumour cells, can promote metastasis in vivo. ${ }^{96}$ Macrophages also are important in supporting multiple myeloma, other haematological malignancies, and metastatic tumours through contact-mediated and noncontact-mediated mechanisms, ${ }^{97}$ while the effect of bone marrow adiposity on tumour niche colonization is a new frontier in cancer research.

Osteoblasts are decidedly vital in maintaining HSC quiescence, but their putative effects on tumour cells are more controversial and include inducing dormancy, cell-cycle arrest, apoptosis, or proliferation, depending on the models, osteoblast cells, culture conditions and tumour cells used. ${ }^{82}$ Osteoblasts might also have an anti-leukaemic role, ${ }^{98}$ and osteoblast numbers are significantly deceased in leukaemia. ${ }^{72}$ Our review published in early 2015 discussed the roles of endosteal osteoblasts and bone marrow adipocytes in myeloma ${ }^{82}$ and others have reviewed this topic for breast and prostate cancers. ${ }^{99}$ The newly appreciated roles of osteocyte signalling, specifically the osteocyte-derived Wnt-inhibitor sclerostin, from lacunae to healthy and cancerous bone marrow niches, has also been reviewed in a 2014 publication. ${ }^{100}$ Targeted reprogramming of interactions between bone marrow cells and tumour cells could prove to be a breakthrough in therapeutic approaches to inhibiting tumour growth in bone.

Within the bone marrow, MSCs have been shown to support tumorigenesis in a plethora of ways, for example by inducing angiogenesis and via secreted chemokine and contactmediated paracrine signalling. MSCs can support growth, increased aggressiveness, and selfrenewal of multiple myeloma, leukaemia, and other solid tumours in vitro and in vivo 
through the activation of pathways such as Akt (protein kinase B), Ras, NFkB, HIF-1a, Myc, human telomerase reverse transcriptase and interferon regulatory factor, ${ }^{101}$ and by creating specific CSC niches through cytokine loops involving IL-6 and platelet basic protein (CXCL7). ${ }^{102}$ Myeloma-associated MSCs are distinctly different in gene expression, function, proliferation and differentiation potential from MSCs from healthy donors, representing one example of how tumour cells manipulate their niche. This abnormal state of myeloma-associated MSCs seems to be induced by multiple myeloma cells, ${ }^{103,104}$ but it is possible that MSCs become abnormal as a pre-myeloma step that could lead to the initiation or propagation of myeloma.

\section{Alterations in the malignant niche}

Normal and malignant niches differ in many ways, depending on the type of tumour colonizing the bone and the extent to which the niche has been altered. In general, the accumulation of malignant cells in the bone marrow interferes with feedback signals for normal haematopoiesis, which results in cytopenia. ${ }^{105}$ In osteolytic niches, which are common with breast cancer and almost exclusively found with multiple myeloma niche colonization, bone formation and resorption activities are uncoupled such that osteoclast activity is increased and osteoblast activity inhibited. In osteoblastic malignant niches, as common with prostate cancer metastasis, the niche is skewed towards increased numbers and activity of osteoblasts and decreased osteoclast activity. As discussed earlier in this article, tumour-associated MSCs are abnormal ${ }^{103}$ and often the immune system is dysregulated, with increased numbers of regulatory $\mathrm{T}$ cells and other immune-inhibiting cells, and decreased activity or numbers of effector $\mathrm{T}$ cells and other cells that have the capacity to kill tumour cells. ${ }^{106}$ Tumour-associated vasculature is often faulty, not only enabling the formation of vessels to feed growing tumours, but also creating leaky neovasculature, making it more difficult to deliver drugs to tumours, many of which become hypoxic and necrotic in the centre once they have grown large enough. ${ }^{107}$ Messenger RNA and microRNA signatures, as well as exosome content and volume from bone marrow stroma, were also found to be abnormal in samples from patients with multiple myeloma. ${ }^{104,108}$ Notch receptor signalling ${ }^{109}$ (a critical regulator of HSC fate and differentiation in the bone marrow) and the SDF1-CXCR4 axis are often deviant, ${ }^{110}$ extracellular matrix components and ratios are often abnormal, ${ }^{111}$ and changes in glycosylation of cell-surface adhesion molecules such as selectin ligands, integrins and mucins, ${ }^{112}$ in cells of the bone marrow are often observed in malignant niches.

\section{Haematopoietic stem cells and tumour cells}

\section{Parallels in niche homing and colonization}

Although the 'vicious cycle' propagates through destructive mechanisms that are absent from healthy HSC-bone marrow interactions, the initial stages of homing to the bone marrow progress similarly for HSCs and tumour cells (Figure 2b). Many of the same pathways, proteins, and adhesion molecules involved in HSC trafficking to the bone marrow niche are used by metastatic tumour cells, and both cell types show a preference for the highly vascularized metaphysis of the bone. ${ }^{113}$ Rather than central marrow, the endosteum seems to be the preferential site for HSCs and tumour cells. ${ }^{114}$ Ligand-receptor interactions 
of adhesion molecules, such as SDF1-CXCR4, ${ }^{115}$ integrin a-4-VCAM-1, CD44osteopontin, and integrin $\alpha_{v} \beta_{3}$-bone sialoprotein, ${ }^{116}$ are important in the homing of HSCs and tumour cells to bone. ${ }^{117}$ Calcium receptors also have a role in the niche-homing of HSCs and in the homing and proliferation of cancer cells. ${ }^{117}$ PSGL-1 is expressed at high levels in multiple myeloma cells and its interaction with selectins in the bone marrow enhances adhesion and homing of these cells. Altered glycosylation and expression of sialyltransferases in multiple myeloma cells also affects their adhesion and migration, specifically into the bone marrow. ${ }^{111,118}$

Bone metastasis-specific patterns of messenger RNA and microRNA expression within cancer cells often contain similarities to those of HSCs, providing additional insight into how tumour cells mimic HSCs in homing to bone marrow. ${ }^{79,91,119}$ On a larger scale, physical features of the bone marrow microenvironment, including acidic $\mathrm{pH}$, high extracellular calcium concentrations, and adjacent sinusoidal blood vessels, also enhance bone colonization by tumour cells (as they do for HSCs) and contribute to the vicious cycle, as described previously. ${ }^{91,120}$ Hypoxia has been implicated both in the induction of tumour quiescence ${ }^{74}$ and in egress of tumour cells from the marrow; ${ }^{121}$ these effects, often driven by HIF signalling, are also seen in HSCs. ${ }^{121-123}$ As described above, hypoxia is a characteristic of the bone marrow, but whether the HSC niche (or tumour-homing niche) is always or necessarily hypoxic is still contentious, as HSCs and tumour cells are often found in close proximity to blood vessels. ${ }^{124}$ Nonetheless, hypoxia, via HIF-1a, can induce quiescence in HSCs and tumour cells by suppressing mitochondrial oxidative metabolism and promoting anaerobic glycolysis, which is thought to be the main source of ATP in HSCs. ${ }^{124} \mathrm{HIF}-1 \mathrm{a}$ has also been shown to be constitutively expressed by multiple myeloma cells in $35 \%$ of patients, independent of actual hypoxic conditions; furthermore, an antisense oligonucleotide inhibiting HIF-1a induced permanent cell-cycle arrest in multiple myeloma cells in preclinical studies, ${ }^{125}$ suggesting that targeting HIF-1a in multiple myeloma cells, in either hypoxic or nonhypoxic environments, could hold great clinical promise. The bone marrow microenvironment also induces quiescence and drug resistance in tumour cells in the bone marrow, owing in part to metabolic changes such as increased expression of HIF-1a and LDH-A. ${ }^{126}$

\section{Competition for the niche}

Numerous studies have demonstrated that multiple myeloma or bone-metastatic tumour cells compete with HSCs for the niche, inhibiting haematopoiesis by displacing HSCs (Figure 2c). ${ }^{95}$ Bone-metastatic prostate cancer cells have been described as 'parasitizing' the bone marrow niche; via annexin A2 and its corresponding receptor, these cells bind to osteoblasts and become quiescent. ${ }^{127}$ Binding of prostate cancer cells to osteoblasts can also induce expression of TANK binding kinase 1 (TBK1), which leads to drug resistance via mTOR inhibition. ${ }^{128}$ Prostate cancer cells seem to displace resident HSCs from the niche, ${ }^{129}$ and patients with multiple myeloma have been found to have decreased numbers of haematopoietic progenitor cells. ${ }^{130}$ These and other studies demonstrate that tumour infiltration inhibits marrow haematopoiesis and can cause anaemia, leukopenia and bone marrow failure by competing with mature haematopoietic cells and HSCs for the same niche. ${ }^{131}$ 
As prostate cancer is one of the only bone-metastatic tumours to cause osteoblastic bone disease, the interactions between prostate cancer and the niche are probably very different from interactions between osteolytic tumours (multiple myeloma and breast cancer) and the niche. The effects of osteoblasts within the HSC niche on the quiescence and drug resistance of disseminated prostate cancer cells suggests that the induction of more osteoblasts would be advantageous to these tumours. Breast cancer and myeloma cells that hijack the HSC niche would presumably gain the same advantages, yet breast cancer and multiple myeloma cells do not increase osteoblast numbers but rather inhibit osteoblast differentiation; this difference suggests that osteolytic tumours benefit more from tipping the balance towards osteoclastic activity than from inducing more bone marrow niches. ${ }^{132}$ The reasons for the development of osteolytic versus osteoblastic lesions, and the differential effects of these lesions on the niche, requires further investigation.

\section{Pre-metastatic niches}

Bone loss in malignant or nonmalignant disease is caused by an imbalance between bone formation and bone resorption; increased osteoclast resorption and/or reduced osteoblast bone formation causes pain, hypercalcemia, fracture, and disrupted haematopoiesis. ${ }^{132}$ The bone marrow niche becomes dysfunctional in malignant and nonmalignant bone diseases, and niche dysfunction is also a potential initiator of these diseases - a dilemma that often complicates aetiology and determination of disease origin. Several studies have shown that changing the bone microenvironment before the introduction of cancer cells, using either bortezomib (a bone anabolic agent) in multiple myeloma ${ }^{133}$ or breast cancer models ${ }^{134}$ or anti-SDF1 pretreatment in a multiple myeloma model, ${ }^{115}$ can make it a less-hospitable environment for tumours.

The concept of a pre-metastatic niche, or an area that is altered to create an environment specific for metastasis before tumour cells physically arrive, has some provocative support, both in the bone marrow and in other regions (Figure 2d). ${ }^{135}$ By sending out signals to the bone marrow, tumour cells may precondition the niche to facilitate its later colonization. Evidence of this phenomenon has come from a 2015 breast cancer study showing that tumour-secreted protein-lysine 6-oxidase (lysyl oxidase) can cause the formation of premetastatic niches in the distant bone marrow by modulating osteoclasts and osteoblasts, and by stimulating osteolysis (hence initiating the vicious cycle), before tumour cells arrive. ${ }^{136}$ In another breast cancer study, peripheral blood serum from patients with cancer significantly supported tumour growth and trans-endothelial migration, compared with serum from healthy donors, and contained higher concentrations of PDGF-AB, intercellular adhesion molecule 1 and vascular cell adhesion protein 1 , which could aid tumour extravasation, bone resorption and proliferation. ${ }^{137}$ Signals from tumour cells can be transmitted in exosomes or other microvesicles or by circulating free DNA to create distant pre-metastatic niches. ${ }^{138-140}$ MSCs have also been found to be recruited to regions of premetastatic niches and, through prostaglandin E2 induced by primary tumour-derived VEGF, create a region more susceptible to tumour colonization. ${ }^{141}$ Kerr et al. ${ }^{142}$ have shown that platelets are pivotal for tumour communication with the bone marrow when creating a premetastatic niche, whereas others have found bone-marrow-derived myeloid cells to be crucial in creating pre-metastatic niches in lung. ${ }^{135,143}$ In summary, it seems that tumours 
probably induce systemic changes and emit systemic signals to hijack, remodel and support tumour-cell colonization of the bone marrow niche. ${ }^{144}$

\section{Niche-directed carcinogenesis}

Not only does the bone marrow niche support metastatic tumour cells arriving from distant locations, but it might also have a role in the first tumorigenic event of oncogenesis (Figure 2e). A 2010 study by Raaijmakers et al. ${ }^{145}$ demonstrated that alterations to the normal HSC niche (via deletion of Dicer1 specifically in mouse osteoprogenitors, but not in mature osteoblasts) disrupts the integrity of haematopoiesis and induces myelodysplasia and secondary leukaemia. A subsequent review article by Raaijmakers summarizes much of the work examining how modulations in ancillary cells of the bone marrow could directly cause leukaemogenesis, myelodysplasia and myeloproliferative disorders through ROS formation (inducing DNA damage), by affecting cell-cycle arrest, or via other pathways. ${ }^{84}$ These data call into question the dogma that cell-autonomous events lead to initiation of cancer, by suggesting that leukaemias might develop through non-cell autonomous pathways, which might be true for other haematological malignancies such as multiple myeloma as well. In summary, the niche might also act as a tumour-enabling milieu by priming or directly initiating tumorigenesis; this concept deserves further investigation.

\section{Recreating the niche experimentally}

Three-dimensional in vitro models are vital to the correct recapitulation of bone and cancer interactions as they more accurately capture the physiological interactions cell-cell signaling within the bone marrow niche than $2 \mathrm{D}$ models. Some researchers have used matrigel ${ }^{146}$ and other hydrogels as 3D substrates to explore the tumour-supportive effects of MSCs and other properties of the niche, or have expanded 2D cultures on cellulose membranes using perfusion bioreactors to create multi-cell layered, although not porous or trabecular-like, bone mimics. ${ }^{147}$ However, to capture the realistic mechanical properties of the trabecular environment in which tumour cells grow in the bone marrow, we and others have utilized harder, mineralizable biomaterials with pores similar to those of trabeculae, such as silk scaffolds, ${ }^{104}$ polycaprolactone-tricalcium phosphate (PCL-TCP) scaffolds, ${ }^{148}$ or calcium phosphate scaffolds, ${ }^{149}$ with or without bioreactors or spinner-flasks. ${ }^{150,151}$ The development and use of bioreactors or spinner-flasks for bone tissue engineering, led by the laboratories of Langer, Kaplan and Vunjak-Novakovic among others, often facilitates better nutrient diffusion of biopsies or tissue-engineered samples, allowing for the development of longer-term models with better osteogenic differentiation and mineralization versus soft, hydrogel models, although with potentially increased challenges for imaging or tumour-cell growth. ${ }^{150-153}$

The vascular niche within the bone marrow is another important area that researchers must recapitulate in the bone marrow in vitro. ${ }^{107}$ In our models, this was done using RFP-labelled human umbilical vein endothelial cells in co-culture with GFP-labelled MM.1S myeloma cells. ${ }^{104}$ Other models include 3D spheroid tri-cultures of osteoblasts, endothelial cells, and prostate cancer cells in microfluidic devices. ${ }^{154}$ Still others have used silk tubes, 
microfluidic devices, megakaryocyte culture systems, and other types of 3D tissue engineering techniques to model the bone marrow vasculature. ${ }^{155-157}$

Many models also exist to study bone marrow metastasis in vivo. For these models, the researcher must decide what to use in terms of the tumour cell line (or primary cells), the model for bone metastasis or growth in the bone marrow, the mouse model and/or strain, and the methods to track tumour burden and bone parameters. Examples of commonly used models of metastasis to the host bone morrow are intravenous injection of the myeloma cell line MM.1S, ${ }^{133,158}$ intracardiac injection of the breast cancer cell line MDA-MB-231, ${ }^{159,160}$ and intracardiac injection of the prostate cancer cell line PC-3. ${ }^{161}$ An advantage of these models is that they recapitulate the latter stages of bone marrow metastasis, including circulation of tumour cells through the bloodstream, rolling and arrest at a distant bone marrow capillary, extravasation across the endothelial lining, colonization of the new microenvironment, proliferation, and hijacking and reprogramming of the bone marrow. As most of these steps are considered rate-limiting, with only a fraction of tumour cells making it through each step, these are typically seen as excellent models for bone metastasis. However, these models do not recapitulate the early stages of bone marrow metastasis, specifically the epithelial-to-mesenchymal transition, escape through the basement membrane, and intravasation (the stage where the cancer cell first enters into circulation), which are all necessary steps of distant metastasis for any solid primary tumour.

Another advantage of the injection models described is that they use human, rather than mouse, tumour cells. However, xenograft models require the use of immunocompromised mice, such as Nod/SCID, NSG, or Rag2 $2^{-/}$mice, and thus cannot accurately capture the roles of the immune system in cancer. Therefore, certain transgenic or syngeneic models (where tumour cells from transgenic mice are directly injected into mice from the same background, to create models of accelerated tumour growth), such as the 5TGM and $\mathrm{Vk} * \mathrm{Myc}$ multiple myeloma models, are often used to preserve the immune system component of the disease. ${ }^{162,163}$

Importantly, injected tumour cells often do not colonize the bone marrow after circulatory injection, for interrelated reasons such as tumour clonality, heterogeneity, lack of the traits necessary for bone-homing and engraftment, and entrapment in the lungs, spleen, or other organs. To get tumour cells to grow within the bone marrow, researchers often must use direct orthotopic injections, omitting the steps of extravasation and bone-homing. For example, Medyouf et al.${ }^{80}$ have developed a primary patient co-transplantation model using a xenotransplant (intrafemoral injection) of tumor cells in sublethally irradiated NSG mice. This elegant work demonstrates the ability of myelodysplastic syndrome disease cells to reprogram progenitors in the bone marrow microenvironment, and illustrates how MSCs facilitate myelodysplastic-cell engraftment-two recurrent themes in the role of MSCs and cancer. Models of direct tumour cell injection into mouse bones (intratibial or intrafemoral) ${ }^{80,164}$ are advantageous in that they contain real, complete, vascularized, functional bone marrow niches; however, the aggressive injection of a bolus of tumour cells into this niche causes inflammation, bone destruction, and formation of a non-vascularized tumour that has not grown or progressed in response to its bone marrow environment (at least initially). Still, after healing, tumour growth within the bone marrow can be studied and 
these models have proven important and effective for studying bone-tumour interactions, understanding bone marrow niche destruction, and developing therapeutics. ${ }^{160}$

Newer models of bone-marrow metastasis use subcutaneously implanted bones, which, depending on the system, allow for: easier optical imaging; a more-controlled environment; the existence of multiple identical bone marrow niches within the same mouse; human bone extracellular matrix and cellular constituents; and a potentially less-inflammatory bone marrow niche (versus direct injection of tumour cells into bone). These models variously use implanted human bone (fetal bone or adult bone from hip replacement surgery; known as a SCID-hu model), ${ }^{165}$ rabbit bone (SCID-rab model), ${ }^{166}$ or mouse bone (Scid-mu model). ${ }^{115}$ Tissue-engineered bone (TE-bone) models from silk scaffolds, ${ }^{108,167-169}$ calcium phosphate scaffolds, ${ }^{149}$ or other biomaterials are also now being utilized as more controllable, reproducible bone-marrow-niche models to investigate the contributions of bone marrow stroma to tumour engraftment or metastasis. For example, one silk-scaffold model utilizes bone marrow stromal cells that are seeded onto silk scaffolds and differentiated into TEbone that can then be used to study breast cancer metastasis. ${ }^{169}$ In this way, different cellular or biochemical components of the bone-marrow microenvironment can be specifically studied for their individual contributions to bone-marrow metastasis. Effects on tumour growth can also be studied by directly injecting tumour cells into TE-bone after implantation or by co-seeding tumour cells into TE-bone cultures before implantation. Paton et al. ${ }^{160}$ have comprehensively reviewed current in vivo myeloma models, and the drawbacks, advantages, and caveats of each.

Challenges remain in fully recapitulating the niche in vivo and in vitro, in part because of the dynamic nature of the microenvironment. As noted, hypoxia is a critical element of the niche, not only for maintaining 'stemness', but also for inducing glycolytic pathways that maintain the vitality of the niche. Hence, the bioenergetic pathways of the niche must be faithfully maintained, which requires very specific nutrient and oxygen concentrations in the media. Similarly the cell-cell interactions described above, whether related to malignant-cell communication with stromal elements or MSC-HSC exchanges, have unique requirements and stages of differentiation that are difficult to restore completely in an artificial environment. Notwithstanding these obstacles, accurate redefinition of the niche in vitro will provide significant insights and important platforms for testing new therapies.

\section{Translational implications}

Disorders of the bone-marrow niche are manifest in several disorders, including myelodysplastic syndromes, myeloproliferative disorders, aplastic anaemias, leukaemias, metastatic diseases, polycythemia vera, and thrombocytosis. Skeletal disorders, including some primary and secondary osteoporotic syndromes, can be considered disorders of the niche. Postmenopausal osteoporosis can be heterogeneous in terms of its aetiology relative to the bone marrow niche. In some women the underlying disorder is an impairment in bone formation, probably attributable to defective MSC recruitment, whereas other women have increased bone resorption with a greater number of $\mathrm{T}$ cells and/or ostemacs with enhanced expression of RANKL and other cytokines. ${ }^{170}$ Thus, drugs for treating osteoporosis that target osteoblasts or their progenitors could have substantial effects on HSCs. The most 
frequently used 'anabolic' agent is $\mathrm{PTH}(1-34)$, which enhances osteoblast differentiation and builds bone mass. ${ }^{171}$ PTH also induces HSC differentiation and can enhance mature peripheral erythroid and myeloid elements. ${ }^{24}$ On the other hand, agents such as bortezomib, a proteasome inhibitor used to treat myeloma, may also induce MSC differentiation into mature osteoblasts, increasing bone mass and reducing myeloma progression in the marrow. ${ }^{133,172}$ As the niche becomes more completely characterized in vivo and recapitulated in vitro, better therapies for chronic haematologic disorders, malignancies and skeletal diseases will undoubtedly emerge.

One offshoot of work to define the bone marrow niche is the therapeutic use of MSCs. Although $~ 400$ trials have been conducted using MSCs to treat a wide range of disorders, neither the FDA nor the European Medicines Agency has yet approved any MSC therapy. ${ }^{2}$ Thus, over the past two decades, despite a plethora of publications and the promise for clinical applications, the role of MSCs in the treatment of heart disease, Alzheimer disease, diabetes mellitus or osteoporosis remains to be determined.

\section{Conclusions}

In summary, the bone marrow niche provides a home for HSCs and MSCs. The niche supports the integration of two major organ systems, the skeleton and the marrow. Even subtle alterations in the niche, whether biochemical, or cytological, can lead to chronic diseases and could affect the host response to, or directly initiate, malignancies. Approaches using MSCs to treat common disorders are still experimental yet are relevant to the design of therapeutics that target the niche. As such, a more-complete understanding of the biology of this unique microenvironment within the bone marrow must, without doubt, continue to be a major research priority.

\section{Acknowledgments}

The authors' work is supported by the NIH/NIAMS (AR066120), NIH/NIDDK (R24 DK092759-01), and by a Pilot Project Grant from NIH/NIGMS (P30GM106391) at the Maine Medical Center Research Institute. The authors' work is also supported in part by the Department of Defense Visionary Postdoctoral Fellowship Award, through the Peer Reviewed Cancer Research Program, under Award FY14 DoD Congressionally Directed Medical Research Programs 30 No. (W81XWH-13-1-0390); opinions, interpretations, conclusions and recommendations are those of the author and are not necessarily endorsed by the DoD.

\section{Biographies}

Clifford J. Rosen MD is a board-certified endocrinologist and basic bone biologist. He received his MD at SUNY Syracuse and completed his residency at U Mass Medical Center Affiliated Hospitals and a fellowship at Dartmouth Medical Center. Dr Rosen is Director of the Center for Clinical and Translational Research and oversees an NIH-funded research laboratory at Maine Medical Center Research Institute, and is as an associate editor of the New England Journal of Medicine. He is past-President of the American Society of Bone and Mineral Research and a former committee member for the Institute of Medicine report on calcium and vitamin D. 
Michaela R. Reagan PhD completed her post-doctoral fellowship at Dana-Farber Cancer Institute/Harvard Medical School in 2015 and is now a Faculty member at the University of Maine and Maine Medical Center Research Institute. She obtained her PhD from Tufts University in Biomedical Engineering and her BS from Harvey Mudd College in general engineering. She is heavily involved with committees and conferences for the Cancer and Bone Society, International Bone and Mineral Society, American Society of Bone and Mineral Research, and American Association for Cancer Research. Her interdisciplinary lab is built on concepts of team science and translational research. Her laboratory is focused on understanding the mechanisms driving multiple myeloma growth and resistance, osteolysis, and cancer-induced bone disease.

\section{References}

1. Ushio-Fukai M, Rehman J. Redox and metabolic regulation of stem/progenitor cells and their niche. Antioxid Redox Signal. 2014; 21:1587-90. [PubMed: 25133592]

2. Bianco P. 'Mesenchymal' stem cells. Annu Rev Cell Dev Biol. 2014; 30:677-704. [PubMed: 25150008]

3. Scadden DT. The stem-cell niche as an entity of action. Nature. 2006; 441:1075-9. [PubMed: 16810242]

4. Miguel MP, De Alcaina Y, Maza DS. de la \& Lopez-Iglesias, P. Cell metabolism under microenvironmental low oxygen tension levels in stemness, proliferation and pluripotency. Curr Mol Med. 2015

5. Gunjal PM, et al. Evidence for induction of a tumor metastasis-receptive microenvironment for ovarian cancer cells in bone marrow and other organs as an unwanted and underestimated side effect of chemotherapy/radiotherapy. J Ovarian Res. 2015; 8:20. [PubMed: 25887079]

6. Meleshina AV, et al. Influence of mesenchymal stem cells on metastasis development in mice in vivo. Stem Cell Res Ther. 2015; 6:15. [PubMed: 25888992]

7. Bianco P, Robey PG, Saggio I, Riminucci M. 'Mesenchymal' stem cells in human bone marrow (skeletal stem cells): a critical discussion of their nature, identity, and significance in incurable skeletal disease. Hum Gene Ther. 2010; 21:1057-1066. [PubMed: 20649485]

8. Méndez-Ferrer $\mathrm{S}$, et al. Mesenchymal and haematopoietic stem cells form a unique bone marrow niche. Nature. 2010; 466:829-34. [PubMed: 20703299]

9. Köhler A, Geiger H, Gunzer M. Imaging hematopoietic stem cells in the marrow of long bones in vivo. Methods Mol Biol. 2011; 750:215-24. [PubMed: 21618094]

10. Manolagas SC, Jilka RL. Bone marrow, cytokines, and bone remodeling. Emerging insights into the pathophysiology of osteoporosis. N Engl J Med. 1995; 332:305-311. [PubMed: 7816067]

11. Bianco $P$, et al. The meaning, the sense and the significance: translating the science of mesenchymal stem cells into medicine. Nat Med. 2013; 19:35-42. [PubMed: 23296015]

12. Wong RSY. Mesenchymal stem cells: angels or demons? J Biomed Biotechnol. 2011; 2011:459510. [PubMed: 21822372]

13. Calvi LM, et al. Osteoblastic cells regulate the haematopoietic stem cell niche. Nature. 2003; 425:841-6. [PubMed: 14574413]

14. Bianco P. Minireview: The stem cell next door: skeletal and hematopoietic stem cell 'niches' in bone. Endocrinology. 2011; 152:2957-62. [PubMed: 21610157]

15. Ellis SL, Nilsson SK. The location and cellular composition of the hemopoietic stem cell niche. Cytotherapy. 2012; 14:135-43. [PubMed: 22107161]

16. Morrison SJ, Scadden DT. The bone marrow niche for haematopoietic stem cells. Nature. 2014; 505:327-34. [PubMed: 24429631]

17. Bianco P, Sacchetti B, Riminucci M. Osteoprogenitors and the hematopoietic microenvironment. Best Pract Res Clin Haematol. 2011; 24:37-47. [PubMed: 21396591] 
18. Sacchetti B, et al. Self-renewing osteoprogenitors in bone marrow sinusoids can organize a hematopoietic microenvironment. Cell. 2007; 131:324-36. [PubMed: 17956733]

19. Morikawa $S$, et al. Prospective identification, isolation, and systemic transplantation of multipotent mesenchymal stem cells in murine bone marrow. J Exp Med. 2009; 206:2483-96. [PubMed: 19841085]

20. Liu Y, et al. Osterix-Cre Labeled Progenitor Cells Contribute to the Formation and Maintenance of the Bone Marrow Stroma. PLoS One. 2013; 8

21. Kim SW, et al. Intermittent parathyroid hormone administration converts quiescent lining cells to active osteoblasts. J Bone Miner Res. 2012; 27:2075-84. [PubMed: 22623172]

22. Asada N, Katayama Y. Regulation of hematopoiesis in endosteal microenvironments. Int J Hematol. 2014; 99:679-84. [PubMed: 24760425]

23. Huber BC, Grabmaier U, Brunner S. Impact of parathyroid hormone on bone marrow-derived stem cell mobilization and migration. World J Stem Cells. 2014; 6:637-43. [PubMed: 25426261]

24. Kuznetsov SA, et al. The interplay of osteogenesis and hematopoiesis: expression of a constitutively active PTH/PTHrP receptor in osteogenic cells perturbs the establishment of hematopoiesis in bone and of skeletal stem cells in the bone marrow. J Cell Biol. 2004; 167:111322. [PubMed: 15611335]

25. Coşkun S, et al. Development of the fetal bone marrow niche and regulation of HSC quiescence and homing ability by emerging osteolineage cells. Cell Rep. 2014; 9:581-90. [PubMed: 25310984]

26. Omatsu Y, Seike M, Sugiyama T, Kume T, Nagasawa T. Foxc1 is a critical regulator of haematopoietic stem/progenitor cell niche formation. Nature. 2014; 508:536-40. [PubMed: 24590069]

27. Rosen CJ, Ackert-Bicknell C, Rodriguez JP, Pino AM. Marrow fat and the bone microenvironment: developmental, functional, and pathological implications. Crit Rev Eukaryot Gene Expr. 2009; 19:109-124. [PubMed: 19392647]

28. Rosen CJ, Bouxsein ML. Mechanisms of disease: is osteoporosis the obesity of bone? Nat Clin Pract Rheumatol. 2006; 2:35-43. [PubMed: 16932650]

29. Gordon MY. Stem cells and the microenvironment in aplastic anaemia. Br J Haematol. 1994; 86:190-2. [PubMed: 8011528]

30. Fazeli PK, et al. Marrow fat and bone-new perspectives. J Clin Endocrinol Metab. 2013; 98:935945. [PubMed: 23393168]

31. Scheller EL, Rosen CJ. What's the matter with MAT? Marrow adipose tissue, metabolism, and skeletal health. Ann N Y Acad Sci. 2014; 1311:14-30. [PubMed: 24650218]

32. Naveiras $\mathrm{O}$, et al. Bone-marrow adipocytes as negative regulators of the haematopoietic microenvironment. Nature. 2009; 460:259-63. [PubMed: 19516257]

33. Scheller EL, et al. Use of osmium tetroxide staining with microcomputerized tomography to visualize and quantify bone marrow adipose tissue in vivo. Methods Enzymol. 2014; 537:123-39. [PubMed: 24480344]

34. Bredella MA, et al. Determinants of bone microarchitecture and mechanical properties in obese men. J Clin Endocrinol Metab. 2012; 97:4115-4122. [PubMed: 22933540]

35. Cawthorn WP, et al. Bone Marrow Adipose Tissue Is an Endocrine Organ that Contributes to Increased Circulating Adiponectin during Caloric Restriction. Cell Metab. 2014; :1-8. DOI: 10.1016/j.cmet.2014.06.003

36. Bornstein S, et al. FGF-21 and Skeletal Remodeling During and After Lactation in C57BL6 Mice. Endocrinology. 2014; en20141083. doi: 10.1210/en.2014-1083

37. Ackert-Bicknell CL, et al. Strain-specific effects of rosiglitazone on bone mass, body composition, and serum insulin-like growth factor-I. Endocrinology. 2009; 150:1330-1340. [PubMed: 18948404]

38. Chang MK, et al. Osteal tissue macrophages are intercalated throughout human and mouse bone lining tissues and regulate osteoblast function in vitro and in vivo. J Immunol. 2008; 181:1232-44. [PubMed: 18606677]

39. Winkler IG, et al. Bone marrow macrophages maintain hematopoietic stem cell (HSC) niches and their depletion mobilizes HSCs. Blood. 2010; 116:4815-28. [PubMed: 20713966] 
40. Alexander KA, et al. Osteal macrophages promote in vivo intramembranous bone healing in a mouse tibial injury model. J Bone Miner Res. 2011; 26:1517-32. [PubMed: 21305607]

41. Pettit AR, Chang MK, Hume DA, Raggatt LJ. Osteal macrophages: a new twist on coupling during bone dynamics. Bone. 2008; 43:976-82. [PubMed: 18835590]

42. Casanova-Acebes M, A-González N, Weiss LA, Hidalgo A. Innate immune cells as homeostatic regulators of the hematopoietic niche. Int J Hematol. 2014; 99:685-94. [PubMed: 24634109]

43. Baschuk N, Rautela J, Parker BS. Bone specific immunity and its impact on metastasis. Bonekey Rep. 2015; 4:665. [PubMed: 25908968]

44. Garhyan J, et al. Preclinical and Clinical Evidence of Mycobacterium tuberculosis Persistence in the Hypoxic Niche of Bone Marrow Mesenchymal Stem Cells after Therapy. Am J Pathol. 2015; 185:1924-34. [PubMed: 26066709]

45. Wesseling-Perry K. The BRC canopy: an important player in bone remodeling. Am J Pathol. 2014; 184:924-6. [PubMed: 24561288]

46. Jensen PR, Andersen TL, Hauge EM, Bollerslev J, Delaissé JM. A joined role of canopy and reversal cells in bone remodeling--lessons from glucocorticoid-induced osteoporosis. Bone. 2015; 73:16-23. [PubMed: 25497571]

47. Méndez-Ferrer S, Lucas D, Battista M, Frenette PS. Haematopoietic stem cell release is regulated by circadian oscillations. Nature. 2008; 452:442-7. [PubMed: 18256599]

48. Kotova PD, et al. Functional expression of adrenoreceptors in mesenchymal stromal cells derived from the human adipose tissue. Biochim Biophys Acta. 2014; 1843:1899-908. [PubMed: 24841820]

49. Xie Y, et al. Detection of functional haematopoietic stem cell niche using real-time imaging. Nature. 2009; 457:97-101. [PubMed: 19052548]

50. Hu X, et al. Severe hypoxia exerts parallel and cell-specific regulation of gene expression and alternative splicing in human mesenchymal stem cells. BMC Genomics. 2014; 15:303. [PubMed: 24758227]

51. Krock BL, et al. The aryl hydrocarbon receptor nuclear translocator is an essential regulator of murine hematopoietic stem cell viability. Blood. 2015; 125:3263-72. [PubMed: 25855602]

52. Forristal CE, Levesque JP. Targeting the hypoxia-sensing pathway in clinical hematology. Stem Cells Transl Med. 2014; 3:135-40. [PubMed: 24371328]

53. Winkler IG, et al. Positioning of bone marrow hematopoietic and stromal cells relative to blood flow in vivo: serially reconstituting hematopoietic stem cells reside in distinct nonperfused niches. Blood. 2010; 116:375-85. [PubMed: 20393133]

54. Imanirad P, Dzierzak E. Hypoxia and HIFs in regulating the development of the hematopoietic system. Blood Cells Mol Dis. 2013; 51:256-63. [PubMed: 24103835]

55. Miharada K, et al. Hematopoietic stem cells are regulated by Cripto, as an intermediary of HIF-1a in the hypoxic bone marrow niche. Ann N Y Acad Sci. 2012; 1266:55-62. [PubMed: 22901256]

56. D’Angelo G, Duplan E, Boyer N, Vigne P, Frelin C. Hypoxia up-regulates prolyl hydroxylase activity: a feedback mechanism that limits HIF-1 responses during reoxygenation. J Biol Chem. 2003; 278:38183-7. [PubMed: 12876291]

57. Palomäki S, et al. HIF-1a is upregulated in human mesenchymal stem cells. Stem Cells. 2013; 31:1902-9. [PubMed: 23744828]

58. Andrade PZ, et al. Ex vivo expansion of cord blood haematopoietic stem/progenitor cells under physiological oxygen tensions: clear-cut effects on cell proliferation, differentiation and metabolism. J Tissue Eng Regen Med. 2013; n/an/a. doi: 10.1002/term.1731

59. Liu X, et al. Maintenance of mouse hematopoietic stem cells ex vivo by reprogramming cellular metabolism. Blood. 2015; 125:1562-5. [PubMed: 25593337]

60. Kocabas F, Zheng J, Zhang C, Sadek HA. Metabolic characterization of hematopoietic stem cells. Methods Mol Biol. 2014; 1185:155-64. [PubMed: 25062627]

61. Wagegg M, et al. Hypoxia promotes osteogenesis but suppresses adipogenesis of human mesenchymal stromal cells in a hypoxia-inducible factor-1 dependent manner. PLoS One. 2012; 7:e46483. [PubMed: 23029528] 
62. Duan X, et al. Vegfa regulates perichondrial vascularity and osteoblast differentiation in bone development. Development. 2015; doi: 10.1242/dev.117952

63. Regan JN, et al. Up-regulation of glycolytic metabolism is required for HIF1a-driven bone formation. Proc Natl Acad Sci U S A. 2014; 111:8673-8. [PubMed: 24912186]

64. Chang SH, et al. Association between metformin use and transformation of monoclonal gammopathy of undetermined significance to multiple myeloma in U.S. veterans with diabetes mellitus: a population-based cohort study. Lancet Haematol. 2015; 2:e30-e36. [PubMed: 26034780]

65. Jang WG, Kim EJ, Lee KN, Son HJ, Koh JT. AMP-activated protein kinase (AMPK) positively regulates osteoblast differentiation via induction of Dlx5-dependent Runx2 expression in MC3T3E1 cells. Biochem Biophys Res Commun. 2011; 404:1004-9. [PubMed: 21187071]

66. Guntur AR, Le PT, Farber CR, Rosen CJ. Bioenergetics during calvarial osteoblast differentiation reflect strain differences in bone mass. Endocrinology. 2014; 155:1589-1595. [PubMed: 24437492]

67. Esen E, Long F. Aerobic glycolysis in osteoblasts. Curr Osteoporos Rep. 2014; 12:433-8. [PubMed: 25200872]

68. Esen E, Lee S-Y, Wice BM, Long F. PTH Promotes Bone Anabolism by Stimulating Aerobic Glycolysis Via IGF Signaling. J Bone Miner Res. 2015; doi: 10.1002/jbmr.2556

69. Nagasawa T. CXC chemokine ligand 12 (CXCL12) and its receptor CXCR4. J Mol Med (Berl). 2014; 92:433-9. [PubMed: 24722947]

70. Nervi B, Link DC, DiPersio JF. Cytokines and hematopoietic stem cell mobilization. J Cell Biochem. 2006; 99:690-705. [PubMed: 16888804]

71. Nguyen TM, et al. EphB4 Expressing Stromal Cells Exhibit an Enhanced Capacity for Hematopoietic Stem Cell Maintenance. Stem Cells. 2015; doi: 10.1002/stem.2069

72. Krevvata M, et al. Inhibition of leukemia cell engraftment and disease progression in mice by osteoblasts. Blood. 2014; 124:2834-46. [PubMed: 25139351]

73. Kode A, et al. FoxO1-Dependent induction of acute myeloid leukemia by osteoblasts in mice. Leukemia. 2015; doi: 10.1038/leu.2015.161

74. Guise TA, et al. Basic mechanisms responsible for osteolytic and osteoblastic bone metastases. Clin cancer Res an Off J Am Assoc Cancer Res. 2006; 12:6213s-6216s.

75. Weilbaecher KN, Guise TA, McCauley LK. Cancer to bone: a fatal attraction. Nat Rev Cancer. 2011; 11:411-425. [PubMed: 21593787]

76. Cui Q, et al. Targeting myeloma-osteoclast interaction with $\mathrm{V} \gamma 9 \mathrm{~V} \delta 2 \mathrm{~T}$ cells. Int J Hematol. 2011; 94:63-70. [PubMed: 21698356]

77. Le Gall C, et al. A cathepsin K inhibitor reduces breast cancer induced osteolysis and skeletal tumor burden. Cancer Res. 2007; 67:9894-902. [PubMed: 17942921]

78. Jones DH, et al. Regulation of cancer cell migration and bone metastasis by RANKL. Nature. 2006; 440:692-6. [PubMed: 16572175]

79. Roodman GD. Genes associate with abnormal bone cell activity in bone metastasis. Cancer Metastasis Rev. 2012; 31:569-78. [PubMed: 22706844]

80. Medyouf $\mathrm{H}$, et al. Myelodysplastic cells in patients reprogram mesenchymal stromal cells to establish a transplantable stem cell niche disease unit. Cell Stem Cell. 2014; 14:824-37. [PubMed: 24704494]

81. Reagan MR, Ghobrial IM. Multiple myeloma mesenchymal stem cells: characterization, origin, and tumor-promoting effects. Clin Cancer Res. 2012; 18:342-9. [PubMed: 22065077]

82. Reagan MR, Liaw L, Rosen CJ, Ghobrial IM. Dynamic Interplay between Bone and Multiple Myeloma: Emerging Roles of the Osteoblast. Bone. 2015; 75:161-169. [PubMed: 25725265]

83. Schepers K, et al. Myeloproliferative neoplasia remodels the endosteal bone marrow niche into a self-reinforcing leukemic niche. Cell Stem Cell. 2013; 13:285-99. [PubMed: 23850243]

84. Raaijmakers MHGP. Myelodysplastic syndromes: revisiting the role of the bone marrow microenvironment in disease pathogenesis. Int J Hematol. 2012; 95:17-25. [PubMed: 22218882]

85. Shiozawa Y, Taichman RS. Cancer Stem Cells and the Bone Marrow Microenvironment. Bonekey Rep. 2012; 2012 
86. Kang Y, Pantel K. Tumor cell dissemination: emerging biological insights from animal models and cancer patients. Cancer Cell. 2013; 23:573-81. [PubMed: 23680145]

87. Chantry AD, et al. Inhibiting activin-A signaling stimulates bone formation and prevents cancerinduced bone destruction in vivo. J Bone Miner Res. 2010; 25:2633-46. [PubMed: 20533325]

88. Kingsley LA, Fournier PGJ, Chirgwin JM, Guise TA. Molecular biology of bone metastasis. Mol Cancer Ther. 2007; 6:2609-17. [PubMed: 17938257]

89. Kimura T, et al. Targeting of bone-derived insulin-like growth factor-II by a human neutralizing antibody suppresses the growth of prostate cancer cells in a human bone environment. Clin Cancer Res. 2010; 16:121-9. [PubMed: 20028742]

90. Kovacic N, Croucher PI, McDonald MM. Signaling Between Tumor Cells and the Host Bone Marrow Microenvironment. Calcif Tissue Int. 2013; 94:125-39. [PubMed: 24046000]

91. Ottewell PD, O'Donnell L, Holen I. Molecular alterations that drive breast cancer metastasis to bone. Bonekey Rep. 2015; 4:643. [PubMed: 25848532]

92. Suva LJ, Washam C, Nicholas RW, Griffin RJ. Bone metastasis: mechanisms and therapeutic opportunities. Nat Rev Endocrinol. 2011; 7:208-18. [PubMed: 21200394]

93. Martinez-Outschoorn U, Sotgia F, Lisanti MP. Tumor microenvironment and metabolic synergy in breast cancers: critical importance of mitochondrial fuels and function. Semin Oncol. 2014; 41:195-216. [PubMed: 24787293]

94. Olechnowicz SWZ, Edwards CM. Contributions of the host microenvironment to cancer-induced bone disease. Cancer Res. 2014; 74:1625-31. [PubMed: 24599133]

95. Raaijmakers MHGP. Niche contributions to oncogenesis: emerging concepts and implications for the hematopoietic system. Haematologica. 2011; 96:1041-8. [PubMed: 21459792]

96. Dawson MR, Chae SS, Jain RK, Duda DG. Direct evidence for lineage-dependent effects of bone marrow stromal cells on tumor progression. Am J Cancer Res. 2011; 1:144-154. [PubMed: 21822499]

97. Asimakopoulos F, et al. Macrophages in multiple myeloma: emerging concepts and therapeutic implications. Leuk Lymphoma. 2013; 54:2112-21. [PubMed: 23432691]

98. Logothetis CJ, Lin SH. Osteoblasts in prostate cancer metastasis to bone. Nat Rev Cancer. 2005; 5:21-8. [PubMed: 15630412]

99. Hardaway AL, Herroon MK, Rajagurubandara E, Podgorski I. Bone marrow fat: linking adipocyteinduced inflammation with skeletal metastases. Cancer Metastasis Rev. 2014; 33:527-43. [PubMed: 24398857]

100. Compton JT, Lee FY. A Review of Osteocyte Function and the Emerging Importance of Sclerostin. J Bone Joint Surg Am. 2014; 96:1659-1668. [PubMed: 25274791]

101. McMillin DW, et al. Tumor cell-specific bioluminescence platform to identify stroma-induced changes to anticancer drug activity. Nat Med. 2010; 16:483. [PubMed: 20228816]

102. Liu S, et al. Breast Cancer Stem Cells Are Regulated by Mesenchymal Stem Cells through Cytokine Networks. Cancer Res. 2011; 71:614-624. [PubMed: 21224357]

103. Reagan MR, Ghobrial IM. Multiple Myeloma-Mesenchymal Stem Cells: Characterization, Origin, and Tumor-Promoting Effects. Clin Cancer Res. 2012; 18:342-9. [PubMed: 22065077]

104. Reagan MR, et al. Investigating osteogenic differentiation in multiple myeloma using a novel 3D bone marrow niche model. Blood. 2014; 124:3250-9. [PubMed: 25205118]

105. Walenda T, et al. Feedback signals in myelodysplastic syndromes: increased self-renewal of the malignant clone suppresses normal hematopoiesis. PLoS Comput Biol. 2014; 10:e1003599. [PubMed: 24763223]

106. Kawano Y, et al. Targeting the bone marrow microenvironment in multiple myeloma. Immunol Rev. 2015; 263:160-72. [PubMed: 25510276]

107. Moschetta M, et al. Role of endothelial progenitor cells in cancer progression. Biochim Biophys Acta. 2014; 1846:26-39. [PubMed: 24709008]

108. Roccaro AM, et al. BM mesenchymal stromal cell-derived exosomes facilitate multiple myeloma progression. J Clin Invest. 2013; 123:1542-1555. [PubMed: 23454749] 
109. Evans AG, Calvi LM. Notch signaling in the malignant bone marrow microenvironment: implications for a niche-based model of oncogenesis. Ann N Y Acad Sci. 2015; 1335:63-77. [PubMed: 25351294]

110. Van den Berk LCJ, et al. Disturbed CXCR4/CXCL12 axis in paediatric precursor B-cell acute lymphoblastic leukaemia. Br J Haematol. 2014; 166:240-9. [PubMed: 24697337]

111. Glavey SV, et al. The sialyltransferase ST3GAL6 influences homing and survival in multiple myeloma. Blood. 2014; doi: 10.1182/blood-2014-03-560862

112. Glavey SV, et al. The cancer glycome: Carbohydrates as mediators of metastasis. Blood Rev. 2015; doi: 10.1016/j.blre.2015.01.003

113. Ellis SL, et al. The relationship between bone, hemopoietic stem cells, and vasculature. Blood. 2011; 118:1516-24. [PubMed: 21673348]

114. Ottewell PD, O’Donnell L, Holen I. Molecular alterations that drive breast cancer metastasis to bone. Bonekey Rep. 2015; 4:643. [PubMed: 25848532]

115. Roccaro AM, et al. SDF-1 Inhibition Targets the Bone Marrow Niche for Cancer Therapy. Cell Rep. 2014; 9:118-28. [PubMed: 25263552]

116. Harms JF, et al. A small molecule antagonist of the alpha(v)beta3 integrin suppresses MDAMB-435 skeletal metastasis. Clin Exp Metastasis. 2004; 21:119-28. [PubMed: 15168729]

117. Kaplan RN, Psaila B, Lyden D. Niche-to-niche migration of bone-marrow-derived cells. Trends Mol Med. 2007; 13:72-81. [PubMed: 17197241]

118. Sullivan C, et al. Functional ramifications for the loss of P-selectin expression on hematopoietic and leukemic stem cells. PLoS One. 2011; 6:e26246. [PubMed: 22039451]

119. Croset M, Kan C, Clézardin P. Tumour-derived miRNAs and bone metastasis. Bonekey Rep. 2015; 4:688. [PubMed: 25987987]

120. Runnels JM, et al. Optical techniques for tracking multiple myeloma engraftment, growth, and response to therapy. J Biomed Opt. 2011; 16:011006. [PubMed: 21280893]

121. Azab AK, et al. Hypoxia promotes dissemination of multiple myeloma through acquisition of epithelial to mesenchymal transition-like features. Blood. 2012; 119:5782-94. [PubMed: 22394600]

122. Muz B, de la Puente P, Azab F, Luderer M, Azab AK. Hypoxia promotes stem cell-like phenotype in multiple myeloma cells. Blood Cancer J. 2014; 4:e262. [PubMed: 25479569]

123. Xiang L, et al. Hypoxia-inducible factor 1 mediates TAZ expression and nuclear localization to induce the breast cancer stem cell phenotype. Oncotarget. 2014; 5:12509-27. [PubMed: 25587023]

124. Gezer D, Vukovic M, Soga T, Pollard PJ, Kranc KR. Concise review: genetic dissection of hypoxia signaling pathways in normal and leukemic stem cells. Stem Cells. 2014; 32:1390-7. [PubMed: 24496882]

125. Borsi E, et al. Hypoxia inducible factor-1 alpha as a therapeutic target in multiple myeloma. Oncotarget. 2014; 5:1779-92. [PubMed: 24732040]

126. Maiso $\mathrm{P}$, et al. Metabolic signature identifies novel targets for drug resistance in Multiple Myeloma. Cancer Res. 2015; doi: 10.1158/0008-5472.CAN-14-3400

127. Yu C, et al. Prostate cancer and parasitism of the bone hematopoietic stem cell niche. Crit Rev Eukaryot Gene Expr. 2012; 22:131-48. [PubMed: 22856431]

128. Kim JK, et al. TBK1 regulates prostate cancer dormancy through mTOR inhibition. Neoplasia. 2013; 15:1064-74. [PubMed: 24027431]

129. Pedersen EA, Shiozawa Y, Pienta KJ, Taichman RS. The prostate cancer bone marrow niche: more than just 'fertile soil'. Asian J Androl. 2012; 14:423-7. [PubMed: 22367179]

130. Martínez-Jaramillo G, Vela-Ojeda J, Flores-Guzmán P, Mayani H. In vitro growth of hematopoietic progenitors and stromal bone marrow cells from patients with multiple myeloma. Leuk Res. 2011; 35:250-5. [PubMed: 20621354]

131. Bruns I, et al. Multiple myeloma-related deregulation of bone marrow-derived CD34(+) hematopoietic stem and progenitor cells. Blood. 2012; 120:2620-30. [PubMed: 22517906]

132. Mundy GR. Mechanisms of osteolytic bone destruction. Bone. 1991; 12(Suppl 1):S1-6. [PubMed: 1954046] 
133. Swami A, et al. Engineered nanomedicine for myeloma and bone microenvironment targeting. Proc Natl Acad Sci U S A. 2014; 111:10287-92. [PubMed: 24982170]

134. Jones MD, et al. A proteasome inhibitor, bortezomib, inhibits breast cancer growth and reduces osteolysis by downregulating metastatic genes. Clin Cancer Res. 2010; 16:4978-89. [PubMed: 20843837]

135. Kaplan RN, et al. VEGFR1-positive haematopoietic bone marrow progenitors initiate the premetastatic niche. Nature. 2005; 438:820-7. [PubMed: 16341007]

136. Cox TR, et al. The hypoxic cancer secretome induces pre-metastatic bone lesions through lysyl oxidase. Nature. 2015; doi: 10.1038/nature14492

137. Martinez LM, et al. Changes in the peripheral blood and bone marrow from untreated advanced breast cancer patients that are associated with the establishment of bone metastases. Clin Exp Metastasis. 2014; 31:213-32. [PubMed: 24173696]

138. Benito-Martin A, Di Giannatale A, Ceder S, Peinado H. The New Deal: A Potential Role for Secreted Vesicles in Innate Immunity and Tumor Progression. Front Immunol. 2015; 6:66. [PubMed: 25759690]

139. Zhang Y, Wang XF. A niche role for cancer exosomes in metastasis. Nat Cell Biol. 2015; 17:709711. [PubMed: 26022917]

140. Sceneay J, Smyth MJ, Möller A. The pre-metastatic niche: finding common ground. Cancer Metastasis Rev. 2013; 32:449-464. [PubMed: 23636348]

141. Liu S, et al. Vascular endothelial growth factor plays a critical role in the formation of the premetastatic niche via prostaglandin E2. Oncol Rep. 2014; 32:2477-84. [PubMed: 25333935]

142. Kerr BA, McCabe NP, Feng W, Byzova TV. Platelets govern pre-metastatic tumor communication to bone. Oncogene. 2013; 32:4319-4324. [PubMed: 23069656]

143. Phoenix KN, Vumbaca F, Fox MM, Evans R, Claffey KP. Dietary energy availability affects primary and metastatic breast cancer and metformin efficacy. Breast Cancer Res Treat. 2010; 123:333-44. [PubMed: 20204498]

144. Brinton LT, Sloane HS, Kester M, Kelly KA. Formation and role of exosomes in cancer. Cell Mol Life Sci. 2014; 72:659-671. [PubMed: 25336151]

145. Raaijmakers MHGP, et al. Bone progenitor dysfunction induces myelodysplasia and secondary leukaemia. Nature. 2010; 464:852-7. [PubMed: 20305640]

146. Sasser AK, et al. Human bone marrow stromal cells enhance breast cancer cell growth rates in a cell line-dependent manner when evaluated in 3D tumor environments. Cancer Lett. 2007; 254:255-64. [PubMed: 17467167]

147. Mastro AM, Vogler EA. A three-dimensional osteogenic tissue model for the study of metastatic tumor cell interactions with bone. Cancer Res. 2009; 69:4097-100. [PubMed: 19435905]

148. Sieh S, Lubik AA, Clements JA, Nelson CC, Hutmacher DW. Interactions between human osteoblasts and prostate cancer cells in a novel 3D in vitro model. Organogenesis. 6:181-8. [PubMed: 21197221]

149. Maréchal M, et al. Bone augmentation with autologous periosteal cells and two different calcium phosphate scaffolds under an occlusive titanium barrier: an experimental study in rabbits. $\mathbf{J}$ Periodontol. 2008; 79:896-904. [PubMed: 18454669]

150. Augst A, et al. Effects of chondrogenic and osteogenic regulatory factors on composite constructs grown using human mesenchymal stem cells, silk scaffolds and bioreactors. J R Soc Interface. 2008; 5:929-39. [PubMed: 18230586]

151. Marolt D, et al. Bone and cartilage tissue constructs grown using human bone marrow stromal cells, silk scaffolds and rotating bioreactors. Biomaterials. 2006; 27:6138-49. [PubMed: 16895736]

152. Ferrarini M, et al. Ex-vivo dynamic 3-D culture of human tissues in the $\operatorname{RCCS}^{\mathrm{TM}}$ bioreactor allows the study of Multiple Myeloma biology and response to therapy. PLoS One. 2013; 8:e71613. [PubMed: 23990965]

153. Meinel L, et al. Engineering bone-like tissue in vitro using human bone marrow stem cells and silk scaffolds. J Biomed Mater Res A. 2004; 71:25-34. [PubMed: 15316936]

154. Hsiao AY, et al. Microfluidic system for formation of PC-3 prostate cancer co-culture spheroids. Biomaterials. 2009; 30:3020-7. [PubMed: 19304321] 
155. Pallotta I, Lovett M, Kaplan DL, Balduini A. Three-dimensional system for the in vitro study of megakaryocytes and functional platelet production using silk-based vascular tubes. Tissue Eng Part C Methods. 2011; 17:1223-32. [PubMed: 21895494]

156. Wray LS, et al. A silk-based scaffold platform with tunable architecture for engineering criticallysized tissue constructs. Biomaterials. 2012; 33:9214-24. [PubMed: 23036961]

157. Di Buduo CA, et al. Programmable 3D silk bone marrow niche for platelet generation ex vivo and modeling of megakaryopoiesis pathologies. Blood. 2015; 125:2254-64. [PubMed: 25575540]

158. Roccaro AM, et al. CXCR4 Regulates Extra-Medullary Myeloma through EpithelialMesenchymal-Transition-like Transcriptional Activation. Cell Rep. 2015; doi: 10.1016/j.celrep. 2015.06.059

159. Hu Z, Zhang Z, Guise T, Seth P. Systemic delivery of an oncolytic adenovirus expressing soluble transforming growth factor- $\beta$ receptor II-Fc fusion protein can inhibit breast cancer bone metastasis in a mouse model. Hum Gene Ther. 2010; 21:1623-9. [PubMed: 20712434]

160. Paton-Hough J, Chantry AD, Lawson MA. A review of current murine models of multiple myeloma used to assess the efficacy of therapeutic agents on tumour growth and bone disease. Bone. 2015; 77:57-68. [PubMed: 25868800]

161. Van der Horst G, et al. Targeting of a(v)-integrins in stem/progenitor cells and supportive microenvironment impairs bone metastasis in human prostate cancer. Neoplasia. 2011; 13:51625. [PubMed: 21677875]

162. Fowler JA, Mundy GR, Lwin ST, Lynch CC, Edwards CM. A murine model of myeloma that allows genetic manipulation of the host microenvironment. Dis Model Mech. 2009; 2:604-11. [PubMed: 19779066]

163. Chesi M, et al. AID-dependent activation of a MYC transgene induces multiple myeloma in a conditional mouse model of post-germinal center malignancies. Cancer Cell. 2008; 13:167-80. [PubMed: 18242516]

164. Schueler J, et al. Intratibial injection of human multiple myeloma cells in NOD/SCID IL-2R $\gamma$ (null) mice mimics human myeloma and serves as a valuable tool for the development of anticancer strategies. PLoS One. 2013; 8:e79939. [PubMed: 24223204]

165. Tassone $\mathrm{P}$, et al. A SCID-hu in vivo model of human Waldenström macroglobulinemia. Blood. 2005; 106:1341-5. [PubMed: 15886318]

166. Libouban H. The use of animal models in multiple myeloma. Morphologie. 2015; doi: 10.1016/ j.morpho.2015.01.003

167. Goldstein RH, Reagan MR, Anderson K, Kaplan DL, Rosenblatt M. Human bone marrowderived MSCs can home to orthotopic breast cancer tumors and promote bone metastasis. Cancer Res. 2010; 70:10044. [PubMed: 21159629]

168. Reagan MR, et al. Stem Cell Implants for Cancer Therapy: TRAIL-Expressing Mesenchymal Stem Cells Target Cancer Cells in situ. J Breast Cancer. 2012; 15:273-82. [PubMed: 23091539]

169. Moreau JE, et al. Tissue-engineered bone serves as a target for metastasis of human breast cancer in a mouse model. Cancer Res. 2007; 67:10304. [PubMed: 17974972]

170. Manolagas SC. Birth and death of bone cells: basic regulatory mechanisms and implications for the pathogenesis and treatment of osteoporosis. Endocr Rev. 2000; 21:115-137. [PubMed: 10782361]

171. Neer RM, et al. Effect of parathyroid hormone (1-34) on fractures and bone mineral density in postmenopausal women with osteoporosis. N Engl J Med. 2001; 344:1434-41. [PubMed: 11346808]

172. Pennisi A, et al. The proteasome inhibitor, bortezomib suppresses primary myeloma and stimulates bone formation in myelomatous and nonmyelomatous bones in vivo. Am J Hematol. 2009; 84:6-14. [PubMed: 18980173]

173. Lv FJ, Tuan RS, Cheung KMC, Leung VYL. Concise review: the surface markers and identity of human mesenchymal stem cells. Stem Cells. 2014; 32:1408-19. [PubMed: 24578244]

174. Ratajczak MZ. Phenotypic and functional characterization of hematopoietic stem cells. Curr Opin Hematol. 2008; 15:293-300. [PubMed: 18536565]

175. Liu Y, et al. Osterix-Cre labeled progenitor cells contribute to the formation and maintenance of the bone marrow stroma. PLoS ONE. 2013; 8:e71318. [PubMed: 23951132] 


\section{KEY POINTS}

- $\quad$ The bone marrow niche supports the integration of two major organ systems - the skeleton and the marrow

- $\quad$ The bone marrow niche is a unique microenvironment that is crucial for HSC quiescence

- Important features of the niche include its cellular components, hypoxia, extracellular matrices, cytokines and growth factors, and vascularization

- $\quad$ Multiple myeloma and other cancer cells hijack and alter the bone marrow niche, and are altered by the niche in turn; thus, targeting niche-cancer interactions is a promising therapeutic avenue

- $\quad$ Novel in vitro and in vivo models of the bone marrow niche and cancer cells allow us to better understand interactions between cancer and bone marrow niche cells

A more-complete understanding of the biology of the unique bone marrow microenvironment must continue to be a major research priority. 


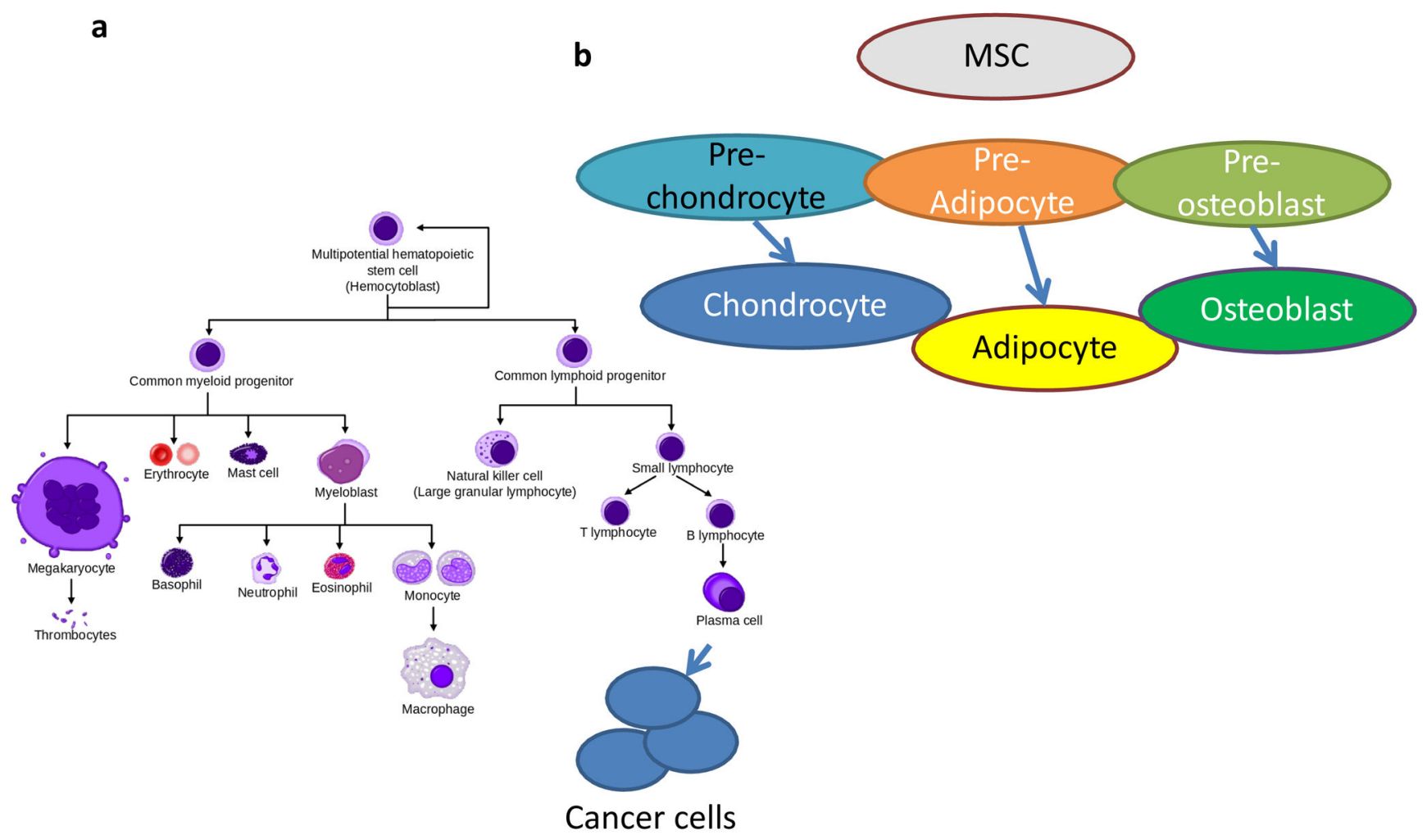

Figure 1. The regenerative cells of the bone marrow niche

a Haematopoietic stem cells (HSCs) give rise to all mature blood cell types. A proportion of these self-renewing cells remain stem cells to maintain a pool of long-term reconstituting HSCs (LT-HSCs) and short-term reconstituting HSCs (ST-HSCs). b | Bone marrow mesenchymal stromal cells (MSCs) are multipotent, self-renewing progenitor cells that can differentiate into other cell types. CLP, common lymphoid progenitor; CMP, common myeloid progenitor; MM cell, multiple myeloma cell; MPP, multipotent progenitor; NK cell, natural killer cell. 


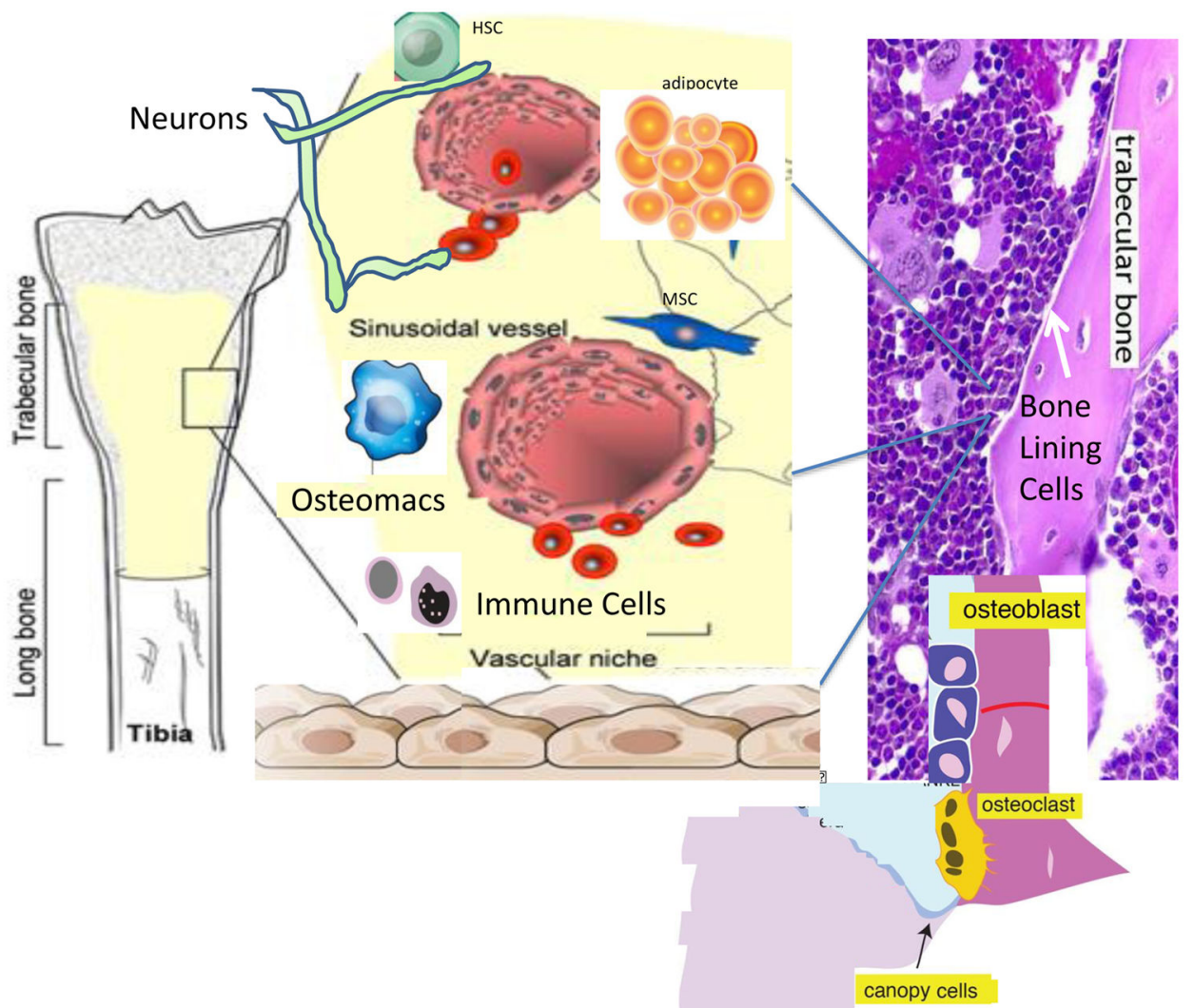

Figure 2. The two mini-organs of the bone marrow niche

The bone marrow niche is composed of multiple cells of mesenchymal and haematopoietic lineages. A hypoxic environment, endosteal bone cells and the proximity of sinusoids and microvessel provide a unique environment for haematopoietic stem cells (HSCs) and mesenchymal stromal cells (MSCs). The union of the skeletal remodelling system and the vascular network within the bone marrow provides a unique niche that regulates whole-body homeostasis. CAR cell, CXCL12-abundant reticular cell. 
The Biochemical Microenvironment of the Niche

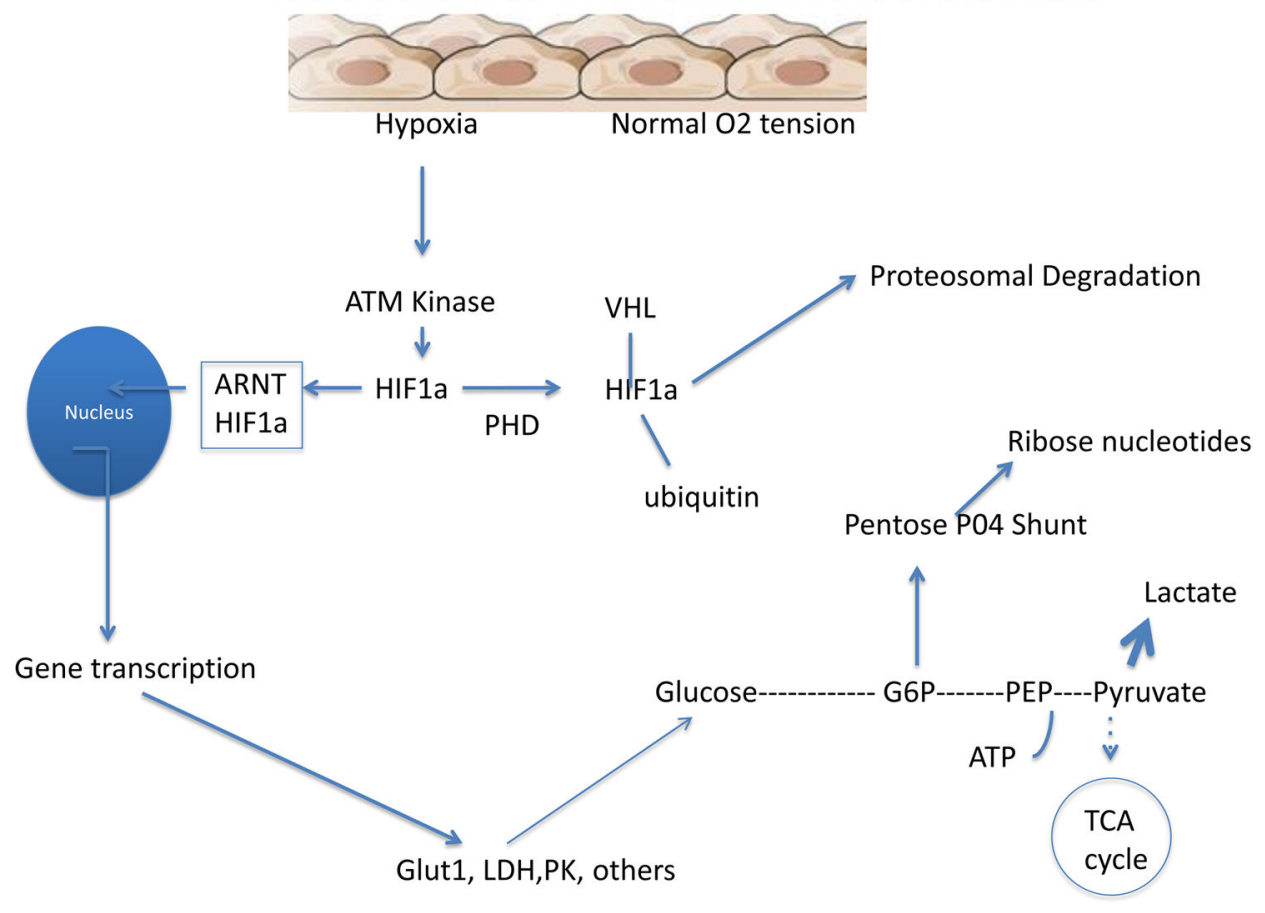

Figure 3. Biochemistry of the bone marrow niche

The hypoxic environment of the niche leads to changes in substrate utilization in order to fuel cellular activity. Hypoxia induces ATM kinase, which catalyzes hypoxia inducible factor-1a (HIF-1a) activity. HIF-1a is stabilized by binding to aryl hydrocarbon receptor nuclear translocator (ARNT); the HIF-1a complex enters the nucleus and regulates a number of genes, particularly those related to glycolysis. Consequently, glucose is utilized for ATP generation through lactate production and via the pentose phosphate shunt for nucleotide synthesis that is essential for cell proliferation. Alternatively, and particularly during normoxia, HIF-1a is rapidly broken down in the proteasome via ubiquitination by proline hydroxylase domain (PHD) enzymes. AMPK, AMP kinase; GLUT1, glucose transporter 1; LDH-A, lactate dehydrogenase A; PK, protein kinase; TCA, tricarboxylic acid; VHL, von Hippel-Lindau tumor suppressor. 


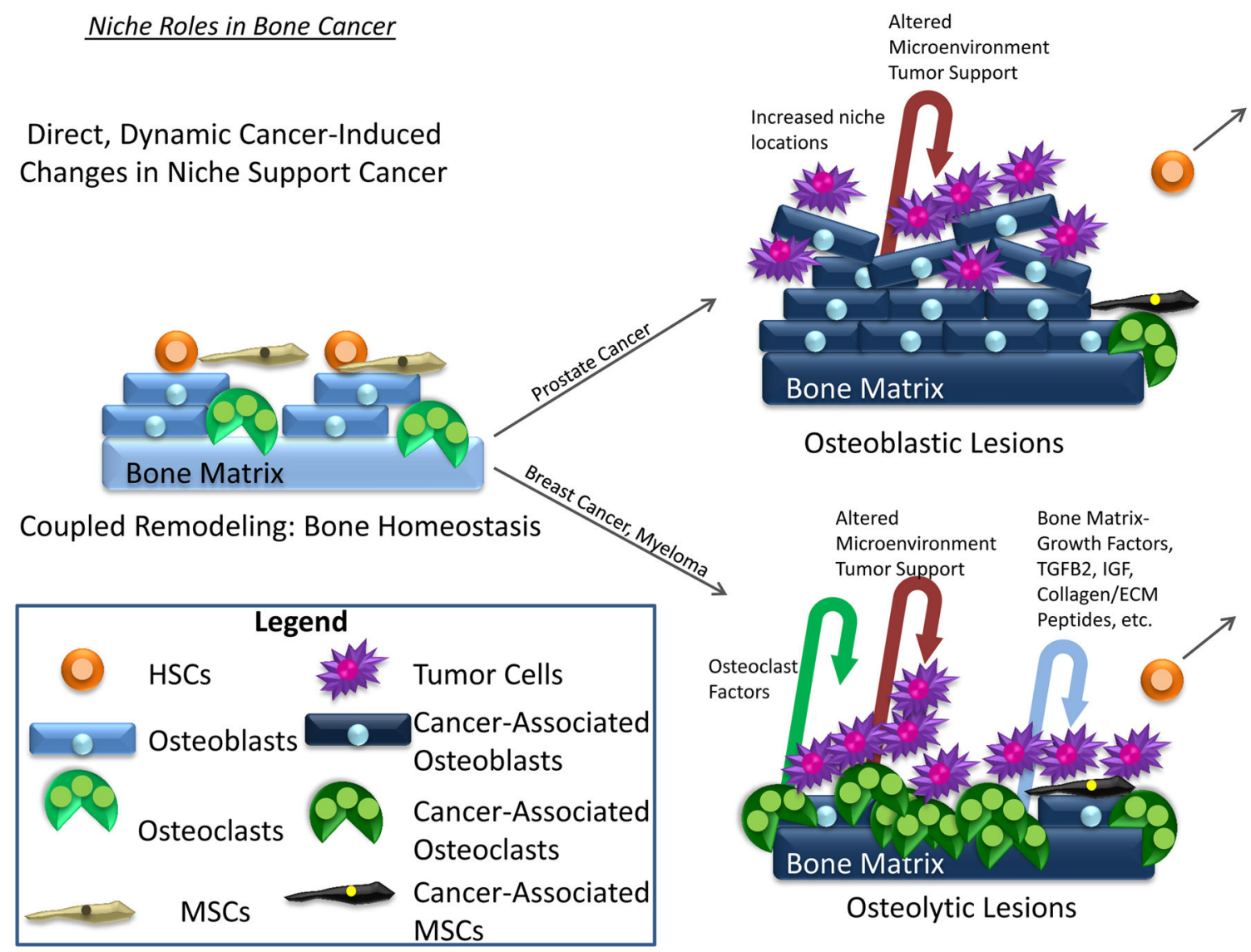

Figure 4. Cancer-related disruption of the bone marrow niche

The niche is an attractive milieu for certain tumour cells, owing to a number of physical, biochemical, cellular, and ionic properties. The relationship between the bone-marrow niche and infiltrating tumour cells is dynamic. a Once tumour cells arrive in the bone marrow, they initiate a forward feedback mechanism to alter and hijack the niche, making the microenvironment even more hospitable for tumour cells. Depending on the tumour type, osteoblastic (increased bone) b | or osteolytic (decreased bone) c | lesions can occur, and feedback to accelerate tumour growth, drug resistance, and protection via dormancy of certain clones. HSC, haematopoietic stem cell; MSC, mesenchymal stromal cell. 
Parallels: HSCs and Tumor Cells Similar Affinity for and homing to the Niche
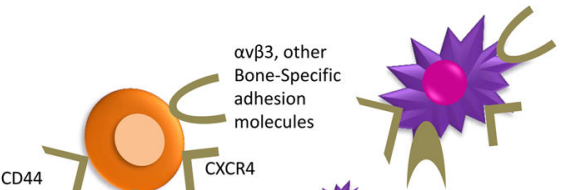

C) Tumors outcompete with HSCs for the Niche to dominate and overtake the niche

HSC niche-homing, engraftment, quiescence, self-renewal. As needed, proliferation, differentiation, and egress.

Figure 5. HSCs and tumour cells compete for the bone marrow niche By mimicking haematopoietic stem cells (HSCs), bone marrow-homing tumour cells often use the same signalling pathways as HSCs to colonize the niche. Eventually, tumour cells outcompete HSCs for the niche, physically displacing present cells and monopolizing the niche to block further homing of HSCs. This leads to disrupted haematopoiesis and subsequent dysregulation of the niche itself. MSC, mesenchymal stromal cell. 


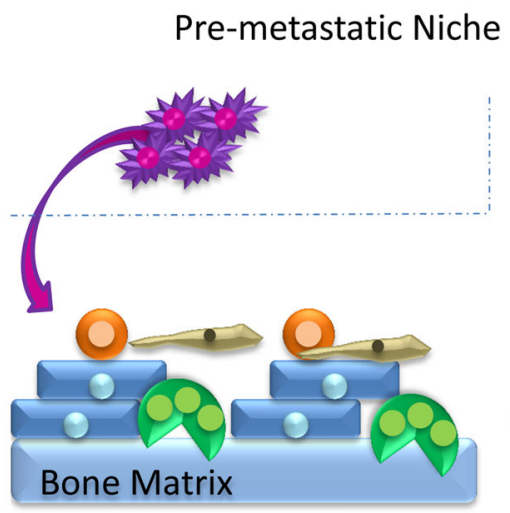

Signaling from Distant Tumors

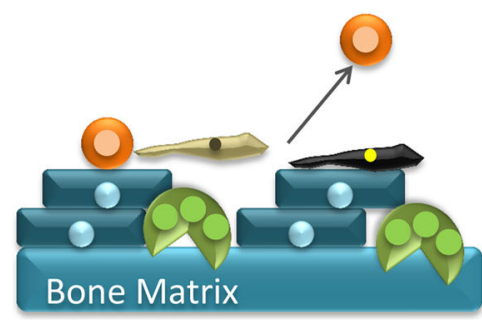

Cancer-Primed Niche

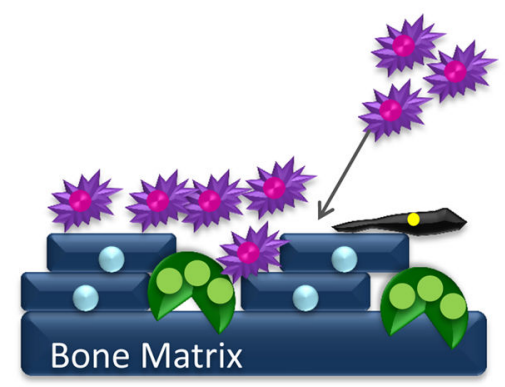

Tumor-Supportive Niche

Figure 6. The premetastatic niche

Alterations in the bone marrow niche can affect the host response to malignancies.

Premetastatic niches can be initiated in the bone marrow by distant tumour cells that send signals (e.g. within exosomes) to precondition the niche, facilitating subsequent tumour-cell infiltration and colonization of the niche. HSC, haematopoietic stem cell; MSC, mesenchymal stromal cell. 
Niche-Directed Carcinogenesis

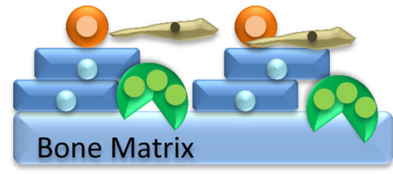

Healthy Niche

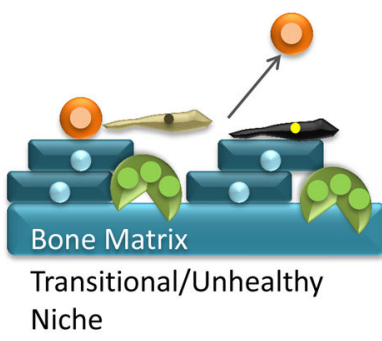

Niche

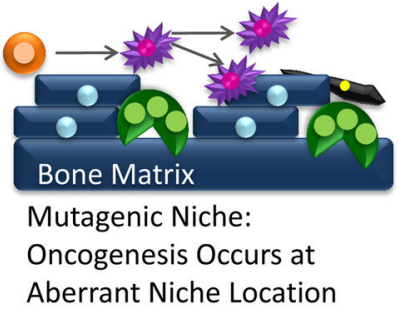

Figure 7. Niche-directed carcinogenesis

Alterations in the bone marrow niche can directly initiate malignant transformation. Nichedirected carcinogenesis is a phenomenon (demonstrated in mice) whereby the niche itself becomes abnormal, which then causes de novo tumorigenesis. Validating this phenomenon in humans will be crucial to understanding the physiological roles of the niche in tumour initiation. HSC, haematopoietic stem cell; MSC, mesenchymal stromal cell. 


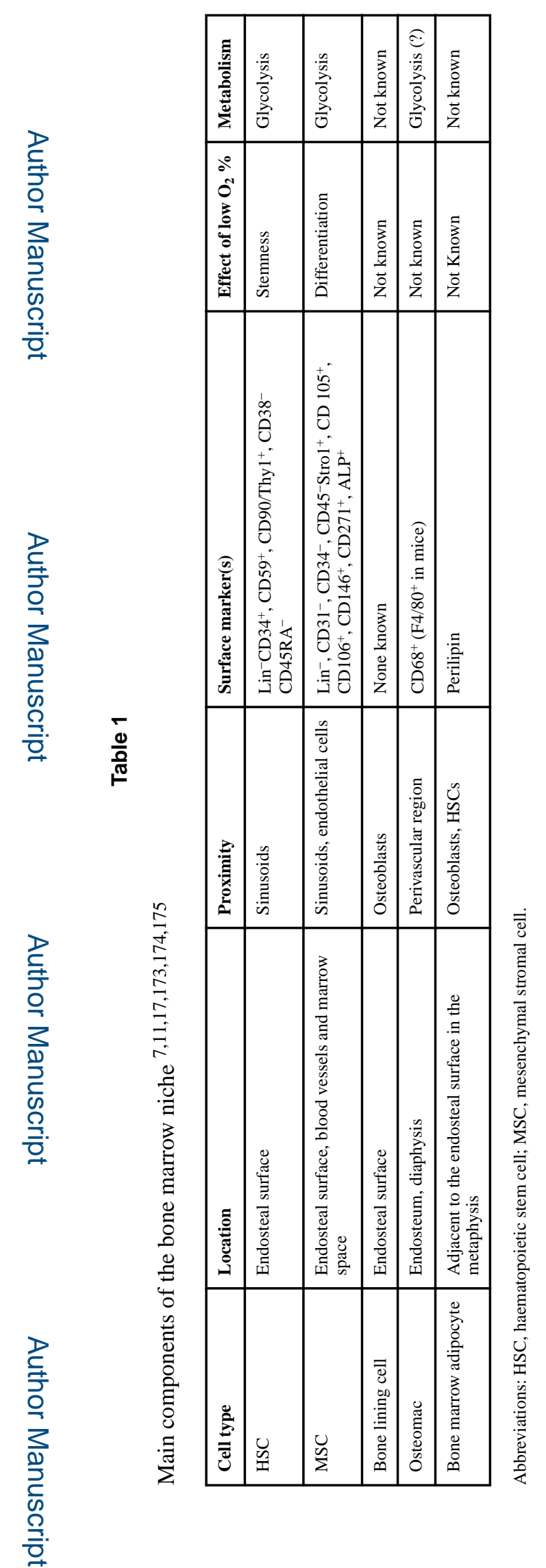

Nat Rev Rheumatol. Author manuscript; available in PMC 2017 March 01. 